AIAA 2002-0504 Advanced Metallic Thermal Protection System Development

M.L. Blosser, R.R. Chen, I.H. Schmidt, J.T. Dorsey,

C.C. Poteet, and R.K. Bird

NASA Langley Research Center

Hampton, VA

40th Aerospace Sciences Meeting \& Exhibit 14-17 January 2002 Reno, Nevada

For permission to copy or to republish, contact the copyright owner named on the first page. For AIAA-held copyright, write to AIAA Permissions Department, 1801 Alexander Bell Drive, Suite 500, Reston, VA, 20191-4344. 



\title{
ADVANCED METALLIC THERMAL PROTECTION SYSTEM DEVELOPMENT
}

\author{
M. L. Blosser, ${ }^{*}$ R. R. Chen, ${ }^{\dagger}$ I. H. Schmidt, ${ }^{\dagger}$ J. T. Dorsey, ${ }^{*}$ C. C. Poteet, ${ }^{*}$ and R. K. Bird" \\ NASA Langley Research Center, Hampton, Virginia
}

\begin{abstract}
$\underline{\text { Abstract }}$
A new Adaptable, Robust, Metallic, Operable, Reusable (ARMOR) thermal protection system (TPS) concept has been designed, analyzed and fabricated. In addition to the inherent, tailorable robustness of metallic TPS, ARMOR TPS offers improved features based on lessons learned from previous metallic TPS development efforts.

A specific location on a single-stage-to-orbit reusable launch vehicle was selected to develop loads and requirements needed to design prototype ARMOR TPS panels. The design loads include ascent and entry heating rate histories, pressures, acoustics, and accelerations. Additional TPS design issues were identified and discussed.

An iterative sizing procedure was used to size the ARMOR TPS panels for thermal and structural loads as part of an integrated TPS/cryogenic tank structural wall. The TPS panels were sized to maintain acceptable temperatures on the underlying structure and to operate under the design structural loading. Detailed creep analyses were also performed on critical components of the ARMOR TPS panels. A lightweight, thermally compliant TPS support system (TPSS) was designed to connect the TPS to the cryogenic tank structure.

Four 18-inch-square ARMOR TPS panels were fabricated. Details of the fabrication process are presented. Details of the TPSS for connecting the ARMOR TPS panels to the externally stiffened cryogenic tank structure are also described. Test plans for the fabricated hardware are presented.
\end{abstract}

\footnotetext{
Aerospace Engineer, Metals and Thermal Structures Branch, Siructures and Materials Competency.

${ }^{+}$Aeronautical Engineer, Lockheed Martin Space Operations.

Copyright C 2001 by the American Institute of Aeronautics and

Astronautics, Inc. No copvright is asserted in the United States under

Title 17, U.S. Code. The U.S. Govemment has a royalty-free license to exercise all rights under the copyright claimed herein for Governmental Purposes. All other rights are reserved by the copyright owner.
}

\section{Introduction}

One of the main goals of NASA is to develop routine, low-cost access to space. Both single-stage-toorbit (SSTO) and two-stage-to-orbit (TSTO) Reusable Launch Vehicles (RLV's) are being studied as a means of achieving this goal. Many technologies' must be developed or enhanced for RLV's to become a viable option for low-cost space access. Unlike the Space Shuttle Orbiter, most orbiters being proposed for fully reusable launch vehicle systems include internal fuel tanks. The integral fuel tanks will result in larger, lower density vehicles with much larger surface areas than the Space Shuttle Orbiter. This larger surface area must not only be protected from aerodynamic heating, but also may be exposed to damage from low-speed impacts during ground operations, launch and landing, on-orbit hypervelocity impacts from micrometeorites and space debris, and rain erosion from low altitude portions of ascent and entry flight trajectories. The large surface area combined with requirements to reduce cost, such as reduced maintenance, reduced turn-around time, operation in a wide range of weather conditions, and longer design life, will require significant advances in thermal protection system (TPS) development.

Metallic thermal protection systems ${ }^{2.3}$ are a key technology that may help achieve the goal of reducing the cost of space access. The inherent ductility and design flexibility of metal TPS offer the potential for a more robust system with lower maintenance costs than competing systems. The foil-gage construction of current metallic TPS concepts makes it simple to improve durability by increasing the thickness of the outer facesheet to meet robustness requirements. Metallic TPS can be designed to prevent water from reaching the internal insulation, thereby eliminating the need for time-consuming re-waterproofing procedures required for current ceramic TPS. The relatively large, mechanically attached metallic TPS panels can be designed to be readily removed for inspection or repair. Most recent high temperature metallic TPS panels have been made from Inconel 617 , with a maximum estimated reuse temperature between $1800^{\circ} \mathrm{F}$ and $1900^{\circ} \mathrm{F}$. Although these peak temperatures are well below those of some competing ceramic TPS systems, they may be adequate for the majority of surfaces on orbiters of proposed fully reusable systems. Large, low 
density orbiters with internal fuel tanks can be flown in entry trajectories that have lower peak heating than the Space Shuttle Orbiter. In addition, other metal alloys may offer advantages over the Inconel used in the current study. Low-density titanium aluminide alloys may offer significant weight savings for peak temperatures below $1500^{\circ} \mathrm{F}$. Iron and nickel aluminides may offer the potential to extend maximum use temperature for metallic TPS to above $2000^{\circ} \mathrm{F}$.

The current paper describes the design, analysis, and fabrication of prototype metallic TPS panels of a new, advanced configuration that functions as part of an integrated TPS/cryogenic tank wall. Design loads and requirements were developed for a specific location on a proposed reusable launch vehicle. An improved metallic TPS design, Adaptable Robust Metallic Operable Reusable (ARMOR) insulation, was developed based on lessons leamed from previous metallic TPS concepts developed during the X-33 program and earlier NASA metallic TPS concepts. The new ARMOR concept has features to eliminate radiation in panel-to-panel gaps, to provide subsurface sealing and attachments, and to decouple deformation and thermal expansion between the inner and outer surfaces. ARMOR TPS panels and associated TPSS were designed to be mounted on an externally stiffened cryogenic tank structure. The insulation in the TPS panels was sized to maintain structural temperatures within acceptable limits. The structural components of the TPS panels were designed and analyzed for acceptable performance under the anticipated aerothermodynamic, acoustic, and inertial loading. Four prototype TPS panels and associated interface hardware were fabricated for future testing.

\section{Loads and Requirements}

The objective of the current effort was to design and build realistic prototype metallic TPS panels that would function as part of an integrated cryogenic tank wall system. A specific location on a proposed RLV was chosen as a basis for calculating realistic thermal and mechanical loading histories. TPS design requirements were developed and loads were calculated for this specific design point.

\section{Reference Vehicle and Structural Component Location}

The vehicle and the location on the vehicle selected for design of an integrated TPS/tank component test article were chosen to satisfy specific TPS and tank considerations. A cylindrical cryogenic tank panel was desired to be consistent with previous optimization studies and to be compatible with the Cryogenic Pressure Box Facility, where the integrated component would be tested under combined thermal and mechanical loads. It was also desirable to have the test article represent a portion of a cryogenic liquid hydrogen $\left(\mathrm{LH}_{2}\right)$ tank to address the integration of TPS and cryogenic tank structure. For the TPS, it was desirable to choose a location as far forward on the vehicle as practical (but behind the carbon-carbon nose cap) where the aerothermal loads (pressures and heating) would be the greatest during entry. Because this is an integrated component, a location was chosen where the TPS was attached to a tank wall. Thus, a location where TPS is attached to the nose fairing or intertank structure would not be acceptable for the current study

The vehicle chosen as a reference for loads was a Wing/Cylindrical-Body Single Stage To Orbit (SSTO) launch vehicle in the VentureStar ${ }^{T M}$ size and payload class $^{4}$ as shown in Figure 1. The Vehicle Analysis Branch (VAB) at NASA Langley Research Center has studied this vehicle, with a gross liftoff weight of 2.9 million $\mathrm{lb}$.

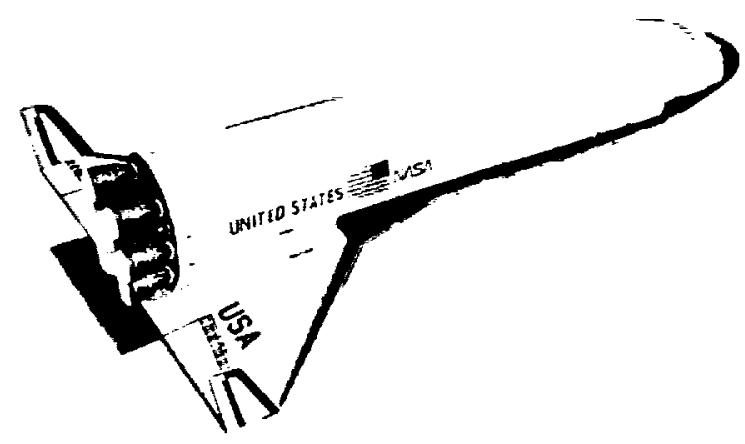

Figure 1: Wing Cylindrical-Body Reusable Launch Vehicle Configuration.

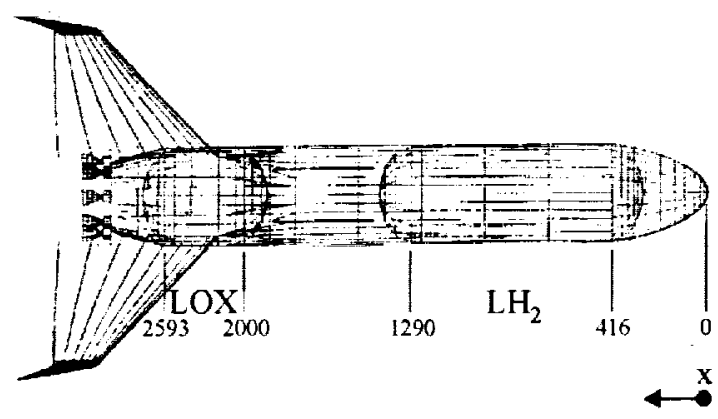

Figure 2: Wing Cylindrical-Body Vehicle Internal Packaging and Dimensions.

The vehicle configuration has a forward $\mathrm{LH}_{2}$ tank, a mid-body payload bay, and an aft Liquid Oxygen (LOX) tank (see Figure 2). The location on the vehicle for defining the component and corresponding loads is 
near the $\mathrm{LH}_{2}$ tank forward-dome/barrel intersection, on the windward side (highest heating) centerline of the cylindrical body, at fuselage station 413 .

\section{TPS Design Requirements}

Because the TPS forms the external surface of an RLV, it must be designed for all the environments experienced by the vehicle. The primary function of the TPS is to protect the vehicle and its contents from aerodynamic heating, so it must be sized to keep internal temperatures within acceptable limits. In addition, the TPS must maintain its structural integrity so that it provides an acceptable aerodynamic surface during all portions of flight through the atmosphere. The TPS panels must therefore be designed to withstand aerodynamic pressure and drag loads, acoustic and dynamic loading from the engines at launch, dynamic pressures that can cause panel flutter, thermal expansion mismatches between the TPS and underlying structure, and strains induced by primary vehicle loads on the underlying structure. The TPS must also have an acceptable risk of failure after lowspeed impacts during launch and hypervelocity impacts from orbital debris in space. Of course, all of these functions must be accomplished while eliminating any unnecessary mass.

In addition to performing all of these thermal and structural functions, the TPS must help reduce overall vehicle costs to enable a viable commercial RLV. Costs can be reduced by lowering initial fabrication and installation costs, reducing required maintenance and repair between flights, reducing turn-around time between flights, and widening the operational envelope of the RLV so that it can spend more time in operation. Therefore, costs can be reduced by developing TPS that requires little inspection, maintenance and repair between flights and that can enable a vehicle to fly through all but the most severe weather. The specific tradeoff between performance (mass) and cost for TPS must be made for each specific RLV to meet its final set of mission and service objectives. However, a proposed set of general requirements that apply to an external TPS system is described in Reference 3 . The detailed requirements used to size the ARMOR TPS are described in Reference 5 and summarized here. For the current study, the ARMOR TPS panels were designed for the anticipated thermal and structural loads, but the cost (and implied robustness) requirements were not well defined enough to be used to size the panels.

\section{Flight Envelope And Load Conditions}

Applied loads on the vehicle are a direct consequence of the ascent and re-entry trajectories flown, the $\mathrm{LH}_{2}$ and LOX tank internal pressure schedules, vehicle accelerations, vehicle acoustics, etc. A complete flight envelope would be defined by flying ascent/entry trajectories for all expected combinations of vehicle velocity/mass combinations and vehicle missions. The full flight envelope would be required for detailed design and optimization of the TPS for flight vehicle. However, to design the current prototype panels, a representative set of load cases were defined from a nominal ascent and entry, as outlined in Reference 3 and detailed in Reference 5. The eight load conditions used were:

1) Liftoff (largest acoustic load)

2) Ascent with maximum heat flux

3) Ascent with maximum static pressure differential (largest pressure load on the TPS panel)

4) Ascent with maximum temperature gradient

5) Ascent with maximum axial acceleration

6) Entry at the initial occurrence of maximum heating rate (when the TPS panel outer surface generally reaches its highest temperature)

7) Entry with maximum static pressure differential (pressure is smaller than during ascent, but panel is warm/hot and properties will be degraded); and,

8) Entry with maximum temperature gradient. These load conditions were chosen as likely to contain the most severe loading for the metallic TPS panels. However, not all of these load conditions ended up contributing to the sizing of the TPS panels.

\section{Aerothermal Environment and Trajectory}

Surface heating rates and pressures for the Wing/Cylindrical Body Vehicle were calculated from trajectory data provided by the Vehicle Analysis Branch at NASA Langley Research Center. The surface pressures and enthalpies provided by VAB were calculated using MINIVER, ${ }^{6}$ an engineering code used to estimate the aerothermal environment of entry vehicles.

Aerothermal heating was calculated using the equation:

$$
q=h\left(H_{r e c}-H_{g}\right)
$$

where $h$, the heat transfer coefficient, and $\mathrm{H}_{\mathrm{ree}}$, the recovery enthalpy, are time dependent quantities obtained from the aerothermal environment data. $\mathrm{H}_{\mathrm{g}}$ is the atmospheric gas enthalpy, and was calculated using the empirical equation:

$$
H_{g}=0.2345 * T+9.786 E-6 * T^{2}+\frac{943.6}{T}-1.57
$$


where units are $B t u, s, f t, R$, and $\mathrm{lbm}$. T is the TPS outer surface temperature. Using the recovery enthalpy technique for thermal analysis is more accurate than applying a heat flux history, because the influence of TPS surface temperature is included. Although slightly less accurate as an applied heat load for thermal analysis, the radiation equilibrium heat flux is a good approximation of the heating to a nearly insulated surface. Figure 3 shows the ascent and entry surface radiation equilibrium heat flux history for the chosen location (STA 413) on the Wing/Cylindrical Body RLV. As for most rocket-powered RLV's most of the aerodynamic heating occurs on entry. The entry heating is typical of a trajectory constrained to limit the maximum heating flux (in this case to avoid overheating the metallic TPS).

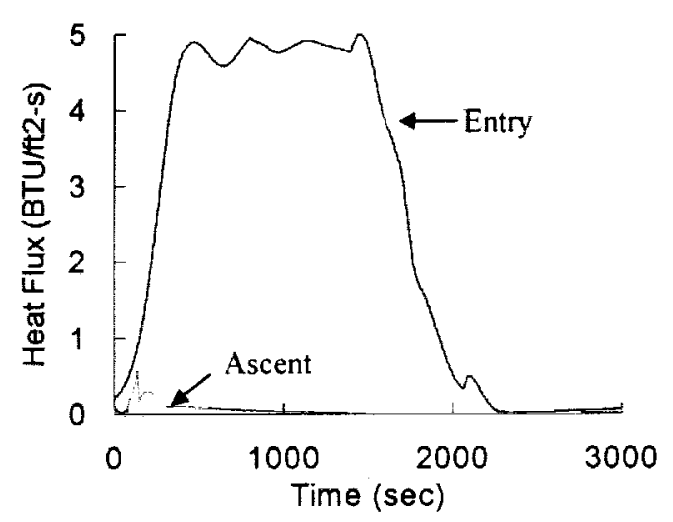

Figure 3: Surface heat flux history.

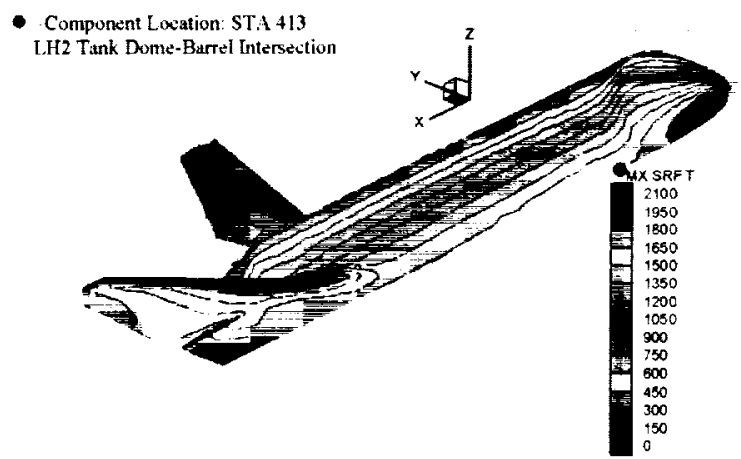

Figure 4: Maximum radiation equilibrium surface temperatures.

The maximum radiation equilibrium temperature distribution for entry, also provided by the Vehicle Analysis Branch at NASA Langley Research Center, is shown in Figure 4. As shown in the figure, the maximum TPS outer surface temperature expected at the component location is between $1500^{\circ} \mathrm{F}$ and $1650^{\circ} \mathrm{F}$.
The predicted static normal aerodynamic pressure at the vehicle surface is one of the outputs of the MINIVER program. The normal pressure difference carried by the TPS panel, $\Delta p$, was calculated by subtracting the local ambient atmospheric pressure from the static normal aerodynamic pressure. (The pressure in the panel interior was assumed to be at the local static pressure). The resulting $\Delta p$ for ascent and entry at STA 413 are shown in Figure 5. MINIVER results are based on compressibility effects in the flow and are not valid at subsonic and transonic flight conditions. Thus, a value of 1.5 was chosen as a cutoff Mach number value, below which MINIVER results were not used. However, the maximum $\Delta p$ on ascent occurs during subsonic or transonic vehicle speeds (depending on location) where the results in Figure 5 are not accurate. As a result, the ascent value shown in Figure 5 was modified using the procedure described in Reference 3 for the ascent maximum $\Delta p$ load condition.

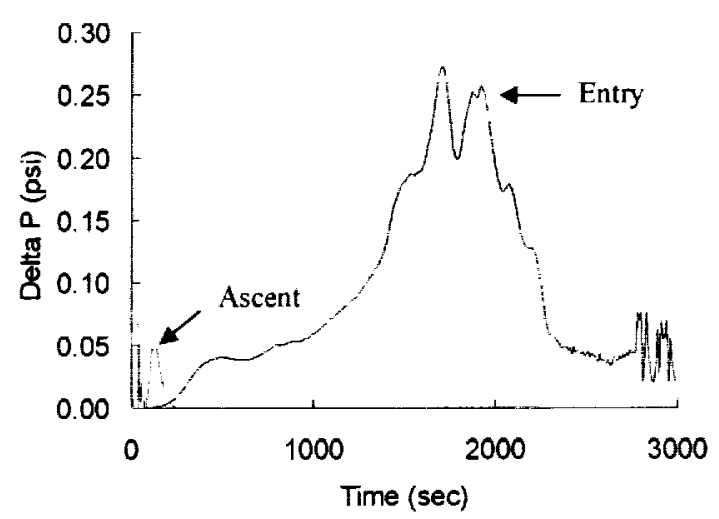

Figure 5: Pressure loading history.

\section{Metallic TPS Concept}

Metallic TPS offers the potential for many design options. The high temperature alloys used for TPS are available in a range of different foil thicknesses that can be fabricated and joined into complex structural shapes. Metallic TPS can be integrated with various types of substructure as described in Reference 3. For a smooth substructure, metallic TPS panels can be directly attached. For externally stiffened structures, a Thermal Protection System Support (TPSS) structure may be required.

\section{TPS Panels}

In the current effort, an improved metallic TPS design was developed using lessons learned from 
previous metallic TPS concepts. Figure 6 shows a sketch of the resulting ARMOR TPS panel.

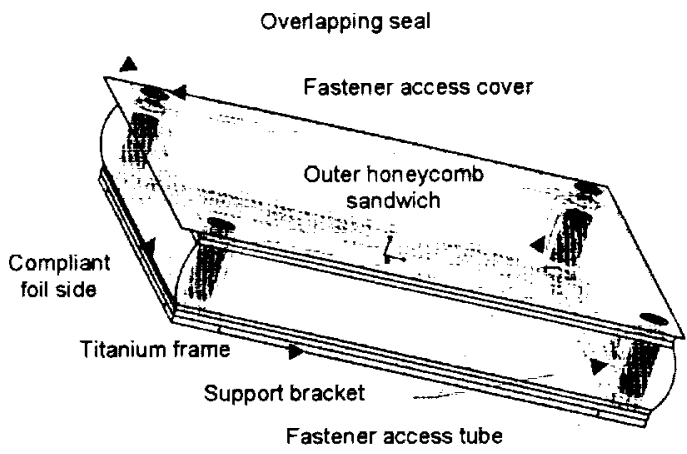

Figure 6: ARMOR TPS panel.

One of the most important components of the ARMOR TPS panel is the outer surface because it forms the outer surface of the vehicle and is directly exposed to the environment. A foil-gage, Inconel 617 metallic honeycomb sandwich panel was chosen for the outer surface because it can efficiently carry the aerodynamic pressures at elevated temperatures and is resistant to oxidation. Other alloys may offer improved performance, but were not available within the schedule and budget of the current effort. The gages of honeycomb sandwich facesheets can be adjusted to increase the surface robustness at the cost of additional weight.

Another key design issue is how to seal between adjacent TPS panels. ARMOR TPS provides three different sealing features: 1) On two edges of the panel, the exterior facesheet of the honeycomb panel extends to overlap the panel-to-panel gap and inhibit ingress of hot gases during reentry. 2) A thin-gage titanium box beam frame defines the edges of the panel's inner surface. These stiff inner edges can be used to compress a lower-temperature felt seal between the TPS panel and underlying structure. 3) Bulged, compliant sides, made of thin gauge metal foil, enclose the sides of the TPS panel and block the radiative heat transfer path in the panel-to-panel gaps. Radiation in panel-to-panel $\operatorname{gaps}^{7}$ can degrade significantly the thermal performance of metallic TPS.

The structural connection between the hot outer surface and the cooler inner surface is a classic thermal/structural design challenge. The connection must provide adequate strength and stiffness to transfer the required mechanical loads, yet must not allow too much heat conduction or develop unacceptable thermal stresses from the difference in thermal expansion between the inner and outer portions of the TPS panel. For the ARMOR TPS panel the outer honeycomb sandwich panel is structurally connected to the inner box beam by a thin Inconel 718 metal support bracket at each comer of the panel. The brackets are arranged tangent to a circle about the center of the panel so that they can accommodate the thermal expansion mismatch by flexing. Each bracket is beaded to prevent buckling when loaded in compression. These brackets are the most highly loaded, and therefore the most critical components of the ARMOR TPS panel.

Another design issue is the attachment of the TPS to the underlying structure. For the ARMOR TPS panel, cool, subsurface mechanical fasteners were chosen. The mechanical fasteners connect the comers of the inner titanium box beam to the substructure. Compliant, bellows-type tubes provide access from the outer surface to the inner mechanical fasteners. Each fastener access tube is closed off at the outer surface by a snap-in Inconel fastener access cover to provide a smooth outer surface. The interior of the fastener access tube is filled with fibrous Saffil alumina fibrous insulation. The holes in the titanium inner frame through which the fasteners attach to the underlying structure are slotted to accommodate the thermal expansion mismatch between the inner TPS panel and the underlying structure

Management of rainwater and moisture is also important for TPS. For the ARMOR TPS, a thin gage metal foil closes out the bottom of the TPS panel to make a watertight container for the internal insulation.

During both ascent and entry the static pressure varies between vacuum and 1 atmosphere. It is important to design the TPS to minimize the difference between the local surface pressure and the internal pressure. A vent, covered by fine mesh, in the metal foil backing allows the TPS internal pressure to be maintained at local atmospheric pressure, but prevents water from entering the panel interior.

The primary function of the TPS is to reduce the aerodynamic heating reaching the underlying structure. For ARMOR TPS, the metallic components carry all mechanical loads, so lightweight, non-load-bearing insulation can be used. The interior of an ARMOR panel is filled with low-density Saffil alumina insulation. Mass could be reduced by using high temperature multilayer insulation; however it was not available within the budget and schedule of the current effort.

\section{ARMOR TPS Integrated with Tank Structure}

In the current study ARMOR TPS was integrated with an externally stiffened composite cryogenic tank structure. A foil-gage titanium TPSS was developed to connect the ARMOR TPS panels to the cryogenic tank structure. 


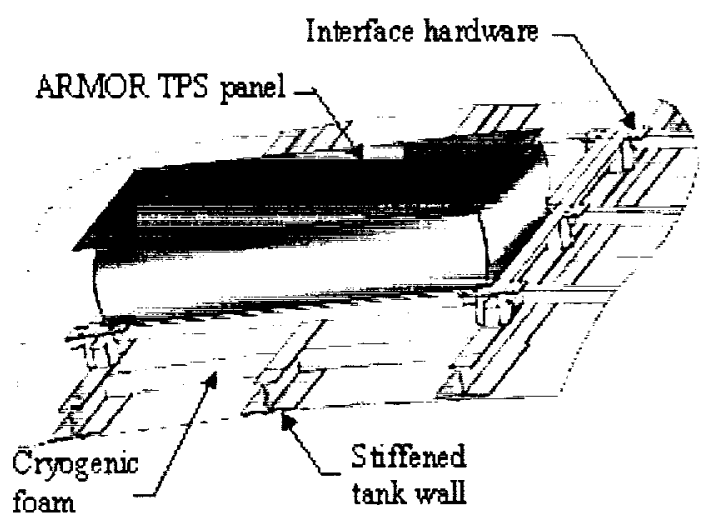

Figure 7: ARMOR TPS integrated with tank structure.

An ARMOR TPS panel is shown assembled on an externally stiffened cryogenic tank structure in Figure 7. A TPSS, or interface structure, connects the TPS panel to the caps of the external stiffeners of the tank wall. There are several design considerations for the TPSS: 1) It must be able to transfer mechanical loads from the TPS panel to the tank structure. 2) It must provide a stiff latticework to support a subsurface seal around the perimeter of each TPS panel. 3) It must have provisions to decouple thermal and mechanical strains in the tank structure from those in the TPS panel while not generating additional thermal stresses from its thermal expansion mismatch with either of the other two components. 4) It must not add too much mass to the system.

The TPSS was made of foil-gage titanium coldformed and spot-welded into the shape described subsequently. Each comer was a built-up assembly of titanium sheet with a machined titanium cap to which the TPS panels were mechanically attached. Two arms of the latticework were spot welded to each comer assembly. Two other receptacles on each comer assembly captured lattice arms from adjacent assemblies while providing a sliding joint to accommodate strain mismatches. Each latticework arm is a titanium sheet box beam spot-welded together. The bottom of each comer assembly is mechanically attached to a tank stringer cap.

TEEK $^{8}$ cryogenic foam insulation is bonded to the outside of the tank between the stiffeners. When attached to the external stiffeners the TPS bottom and cryogenic foam surface form a duct that runs along the length of the vehicle. The duct is purged with gaseous nitrogen during vehicle ground-hold to reduce heat flow into the cryogenic fuel tank and to neutralize any potential tank leaks. After reentry and landing an air purge is performed using blowers attached 30 minutes after vehicle touchdown to cool the blade stiffeners and cryogenic foam insulation surface and to remove heat stored in the TPS panels.

\section{Analysis}

Thermal and structural numerical analyses are required to develop the specific loading conditions from the trajectory information, to size the various components of the TPS panels and to calculate the response of the panels, in detail, to various thermal and mechanical loads. The generation of specific loading conditions and the thermal and structural sizing of various TPS panel components were performed in an iterative manner to arrive at the final panel dimensions. Detailed structural analyses, including creep and panel flutter, ${ }^{9}$ were performed to assess the performance of the resulting TPS panels.

\section{Thermal Finite Element Model}

A one-dimensional transient heat transfer finite element model was created to calculate the temperatures throughout the TPS panel/cryogenic tank assembly and to size TPS Saffil and cryogenic foam insulation layers. Because the TPS panel had not been sized at this point, nominal values were input for the gages of the various elements of the panel (facesheet thicknesses, core thickness, seal bar dimensions, etc.). Running the model using the heating rates shown in Figure 3 resulted in sizing of the cryogenic foam thickness on the tank and the fibrous insulation thickness in the TPS panel, as well as calculated temperature histories for all of the TPS panel elements. The temperature, $\Delta p$, and trajectory information were all used to construct the specific applied load cases.

Figure 8 shows a diagram of the finite element model. (Reference 2 demonstrated that onedimensional models can adequately represent the thermal performance of a metallic TPS panel.) Surfaces are depicted by open circles, and were used to apply boundary conditions and keep track of surface related quantities, such as coating emittance and surface area. Filled circles represent nodes, and lines represent rod heat transfer elements. 
TPS/TPSS/Tank

Conce pt

\section{Ther mal Finite}

Element Model

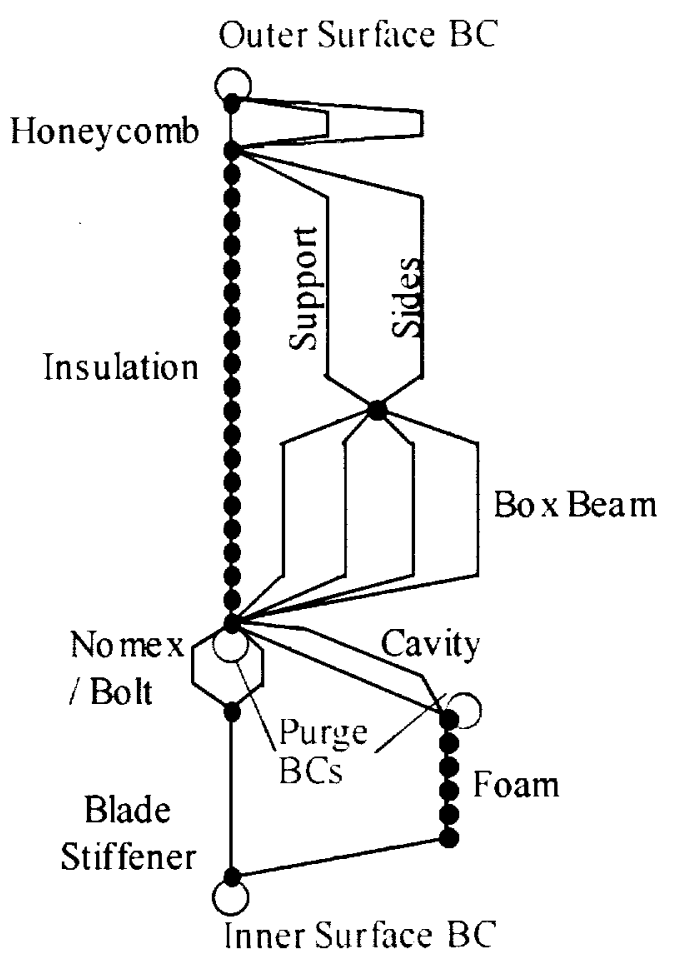

Figure 8: One-dimensional thermal finite element model of TPS/tank assembly.

The honeycomb sandwich on the TPS outer surface was modeled using three rod heat transfer elements connected in parallel, along with increased thermal capacitance at the end nodes to account for facesheet thermal mass. The three elements were used to model solid conduction through the core, gas conduction in the enclosed honeycomb, and radiative heat transfer between the outer and inner facesheets and the core. The solid conductivity was represented by the metal conductivity times the fractional density of the honeycomb core. The gas thermal conductivity was determined using ${ }^{10}$ :

$$
k_{g}=\frac{k_{g}^{*}}{1+2\left(\frac{2-\alpha}{\alpha}\right)\left(\frac{2 \gamma}{\gamma+1}\right)\left(\frac{1}{\operatorname{Pr}}\right)\left(\frac{\lambda}{L_{c}}\right)}
$$

where $k_{g}^{*}$ is the temperature-dependent gas thermal conductivity for air, $\alpha$ is the accommodation coefficient, $\gamma$ is the specific heat ratio, and $\operatorname{Pr}$ is the Prandtl number. $L_{v}$ is the characteristic length of the enclosure, the honeycomb core height. The mean free path, $\lambda$, is given by:

$$
\lambda=\frac{K_{B} T}{\sqrt{2} \pi d_{g}^{2} P}
$$

where $\mathrm{K}_{\mathrm{B}}$ is the Boltzmann constant, $\mathrm{d}_{\mathrm{g}}$ the gas collision diameter, and $T$ and $P$ the temperature and pressure, respectively. Radiation inside honeycomb core was approximated using a rod element with an equivalent conductivity calculated using the equations developed by Swann and Pittman ${ }^{11}$ :

$$
k_{\text {rad }}=4 \zeta \sigma T_{a n g}^{3} L
$$

where $T_{\text {avg }}$ is the average rod element nodal temperature, $\sigma$ is the Stefan-Boltzmann constant, $\mathrm{L}$ is the honeycomb core height, and $\zeta$ is given by:

$$
\zeta=0.664(\eta+0.3)^{(-0.69)} \varepsilon^{1.63(\eta+1)^{(-\infty 89)}}
$$


In this equation, $\varepsilon$ is a uniform emissivity value inside the honeycomb and $\eta$ is given by:

$$
\eta=\frac{L}{d}
$$

where $\mathrm{d}$ is the honeycomb cell size.

Heat transfer through the TPS will be primarily through the insulation layer, due to its large area. The insulation layer is composed of Saffil fibrous insulation. Saffil thermal conductivity is highly pressure dependent, so it was necessary to model both temperature and pressure dependency of the insulation layer material properties.

In addition to heat transfer through the insulation, the heat shorts resulting from the compliant sides and thermally compliant supports were included. The box beam on the lower surface of the TPS was modeled using four elements in parallel to simulate solid conduction through the box beam sides, solid conduction through the mechanical fasteners, gas conduction, and radiation.

ARMOR TPS can be mechanically attached to a TPSS that in turn is mechanically attached to the tank external blade stiffeners. TPSS was modeled by increasing thermal capacitance at the node located at the bottom of the TPS. Two elements in parallel, located between the TPS bottom and the ring frame, were used to model heat transfer through the Nomex felt layer and mechanical fasteners. Heat transfer through the external tank stiffener was modeled with a single element.

A cavity is formed between the back of the TPS panel and the cryogenic foam surface. Heat transfer across the cavity was modeled with two elements in parallel, one modeling gas conduction in an enclosure and the other modeling radiation between infinite parallel plates. Six elements in series were used to model the cryogenic foam insulation layer, and the tank wall was modeled by increasing the thermal capacitance of the innermost node.

\section{Thermal Load Cases}

The boundary conditions were varied to represent the thermal conditions expected during the RLV flight cycle. Three transient thermal load cases were defined: ground hold, ascent, and reentry.

Ground hold analysis assumed the cavity between the back of the TPS panel and the cryogenic foam surface to be purged with gaseous nitrogen. This was simulated by applying convection boundary conditions to the surfaces marked "Purge BCs" in Figure 8. A purge temperature of $-160^{\circ} \mathrm{F}$ was used through most of the ground hold analysis. However, 30 minutes prior to ascent purge temperature was increased to $-110^{\circ} \mathrm{F}$. This has been shown to reduce the weight of purged TPS / tank systems of the configuration studied in this paper. $^{12}$ A heat transfer coefficient of $0.001 \mathrm{Btu} / \mathrm{s}-\mathrm{ft}-\mathrm{R}$ corresponding to a flow rate on the order of $3 \mathrm{ft} / \mathrm{s}$ was used, based on the work reported in Reference 12 . The purge boundary condition drives the node at which it is applied to within a few degrees of the purge gas temperature, effectively acting like a prescribed temperature boundary condition, so that increasing flow rate beyond $3 \mathrm{ft} / \mathrm{s}$ will not significantly influence the results. A prescribed temperature boundary condition was applied to the surface marked "Inner Surface BC" to model the effect of cryogenic fuel, with a temperature of $-433^{\circ} \mathrm{F}$ used to model the cryogenic $\mathrm{LH}_{2}$ fuel. In addition, a convective boundary condition was applied to the surface "Outer Surface BC", allowing convection to ambient air at $70^{\circ} \mathrm{F}$,

The ascent load case did not use the purge boundary condition so the convection boundary conditions were not used. The same cryogenic boundary condition on "Inner Surface BC" used in the groundhold load case was used in the ascent load case. Finally, aerothermal heating and radiation to space boundary conditions were applied on the surface labeled "Outer Surface BC". Radiation to the atmosphere was modeled assuming an emissivity of 0.86 for the coated Inconel 617 TPS surface.

The reentry load case applied aerothermal heating and radiation to space boundary conditions on the "Outer Surface BC" surface. All other surfaces were adiabatic. It takes approximately 50 minutes for the RLV to touch down; however, peak temperatures in the tank wall often occur after touch down. For this reason, it is necessary to extend analysis to simulate the vehicle sitting on the runway. At 50 minutes the boundary condition applied to "Outer Surface BC" was changed from aerothermal heating and radiation to a convection boundary condition with air temperature set at $70^{\circ} \mathrm{F}$. It was assumed that an air purge was initiated in the cavity region 30 minutes after touchdown in order to cool down the TPS and tank, with 30 minutes representing an estimate of a reasonable amount of time to hook up ground based blowers to the RLV. Since the purge is performed in the area of the TPS / tank system that will be most sensitive to over-heating, i.e. the ringframe and cryogenic foam surface, it was assumed that the purge works very quickly to reduce temperatures. The analysis was therefore concluded at the initiation of purging after touchdown.

\section{Insulation Sizing Criteria}

Both the Saffil and the cryogenic foam insulation layers were sized using an iterative thermal analysis, 
increasing or decreasing layer thicknesses until an optimum solution was reached. Saffil insulation thickness was varied until temperature limits in the TPS, TPSS and tank were not exceeded during ascent or reentry load cases with one critical node exactly at the material temperature limit, to within a $+/-5^{\circ} \mathrm{F}$ tolerance. The cryogenic foam insulation thickness was optimized such that heat flow into the cryogenic fuel was under $0.01 \mathrm{Btu} / \mathrm{s}-\mathrm{ft}^{2}$ and air liquefaction was prevented during groundhold and ascent. The heat flux constraint was based on conservative estimates of heat flux into the Space Shuttle external fuel tank. A pressure dependent relation was used to allow accurate determination of air liquefaction conditions during ascent. This becomes an important consideration when purging is performed during groundhold. ${ }^{12}$ A final constraint was placed on the foam filled honeycomb that the minimum thickness equal $0.25 \mathrm{in}$.

\section{Load Table Generation}

When performing combined thermal and structural analysis and sizing, a loads table was generated after each thermal analysis to allow determination of cases to be structurally analyzed. The loads table for windward centerline vehicle station 413 is shown in Table 1. The loads table is used to collect thermal analysis, aerothermal, and trajectory data for several different structural load cases. Load cases were defined for both ascent and reentry. Ascent cases were liftoff, maximum surface heat flux, maximum pressure gradient, maximum thermal gradient, and maximum axial acceleration. Reentry cases were maximum thermal gradient, maximum surface heat flux, and maximum pressure gradient. Data collected for each case includes temperatures, atmospheric pressure, static normal pressure acting on the TPS surface, and vehicle accelerations. Acoustic pressure is calculated based on dynamic pressure, as described in Reference 3.

The pressure gradient acting on the TPS outer honeycomb sandwich panel was determined using the equations:

$$
\begin{aligned}
& \Delta P_{\text {uttimate,TPS+ }}=1.4\left(\Delta P_{\text {aerotynamic }}+3 P_{m s, \text { acoustic }}\right) \\
& \Delta P_{\text {ultimate }, T P S-}=1.4\left(\Delta P_{\text {aerodymamic }}-3 P_{r m s, \text { acoustic }}\right)
\end{aligned}
$$

where $\Delta P_{\text {mutimaut,TPS: }}$ and $\Delta P_{\text {ultimate, TPS- }}$ represent the

\begin{tabular}{|c|c|c|c|c|c|c|c|c|c|}
\hline Trajectory Phase & & Liftodf & $\begin{array}{c}\text { ascent max } \\
\text { qubt }\end{array}$ & $\begin{array}{l}\text { ascent max } \\
\text { delta } P\end{array}$ & \begin{tabular}{|c|} 
ascent $\max \mathrm{T1}$ \\
$\mathbf{T} 2$
\end{tabular} & $\begin{array}{l}\text { ascent } \\
\max a x\end{array}$ & $\begin{array}{c}\text { entry } \\
\text { max_qubt }\end{array}$ & $\begin{array}{c}\text { entry } \\
\text { max_delta_P }\end{array}$ & \begin{tabular}{|c} 
entry max_T1- \\
T2
\end{tabular} \\
\hline Parameter & unit & & & & & & & & \\
\hline Time & $\sec$ & 6 & 364 & 35 & 105 & 165 & 453 & 1705 & 2355 \\
\hline Mach & - & 0.05 & 27.80 & 0.34 & 2.30 & 5.90 & 26.90 & 12.20 & 1.04 \\
\hline Pstatic & psia & $1.47 E+01$ & $1.69 \mathrm{E}-05$ & $1.20 \mathrm{E}+0 \mathrm{I}$ & $9.30 \mathrm{E}-01$ & $490 \mathrm{~F}-02$ & $398 \mathrm{E}-02$ & $2.75 \mathrm{SE}-01$ & $600 \mathrm{E}-01$ \\
\hline Patm & psia & $1.47 E+01$ & $1.69 \mathrm{E}-05$ & $1.19 \mathrm{E}+01$ & $8.82 \mathrm{E}-01$ & $2.77 \mathrm{E}-02$ & $9.70 \mathrm{E}-05$ & $3.23 \mathrm{E}-03$ & $5.50 \mathrm{E}-01$ \\
\hline $\mathrm{TI}$ & $\mathrm{F}$ & 50 & 283 & 48 & 158 & 390 & 1381 & 1197 & 103 \\
\hline $\mathrm{T} 2$ & $F$ & 50 & 288 & 50 & 104 & 377 & 1360 & 1203 & 156 \\
\hline Tbbeam top & $F$ & -85 & -63 & -85 & .86 & -81 & 165 & 252 & 287 \\
\hline lbheam bottom & $\mathrm{F}$ & -106 & -117 & -106 & -107 & -109 & 86 & 171 & 307 \\
\hline Ttpss_top & $\mathrm{F}$ & -114 & -119 & -114 & -114 & -114 & 76 & 147 & 250 \\
\hline Ttank & $\mathrm{F}$ & -427 & -430 & -427 & -429 & -429 & 70 & 86 & III \\
\hline vehicle ax & g's & $0.00 E+00$ & $3.00 \mathrm{E}+00$ & $1.43 \mathrm{E}+00$ & $1.97 \mathrm{E}+00$ & $3.00 \mathrm{E}+\infty 0$ & $-1.20 \mathrm{E}-02$ & $-8.15 \mathrm{E}-02$ & $-4.10 \mathrm{E}-02$ \\
\hline vehicle_ay & g's & $0.00 E+00$ & $0.00 \mathrm{E}+00$ & $0.00 \mathrm{E}+00$ & $0.00 \mathrm{E}+\infty 0$ & $0.00 E+\infty 0$ & $0.00 \mathrm{E}+00$ & $0.00 \mathrm{E}+\infty 0$ & $0.00 \mathrm{E}+00$ \\
\hline vehicle_az & g's & $0.00 E+00$ & $7.11 E-02$ & $-8.1+\mathrm{E}-02$ & $8.70 \mathrm{E}-03$ & $6.49 \mathrm{E}-02$ & $-1.83 \mathrm{E}-0 \mathrm{I}$ & $.1 .24 E+\infty$ & $-1.06 \mathrm{E}+00$ \\
\hline Delta p (aero) & psia & $0.00 E+00$ & $000 \mathrm{E}+00$ & $7.00 \mathrm{E}-02$ & $480 \mathrm{E}-02$ & $2.13 \mathrm{~F}-02$ & $397 \mathrm{E}-02$ & $2.72 \mathrm{E}-01$ & $5,00 \mathrm{E}, \Omega 2$ \\
\hline Delta p(aem - modified $)$ & psia & $0.00 E+00$ & $000 \mathrm{~F}+00$ & 60 (19E-0I & $+17 \mathrm{E}-01$ & $1.85 \mathrm{E}-01$ & $3.97 \mathrm{E}-02$ & $2.72 E-01$ & $5.00 \mathrm{E}-\mathrm{n} 2$ \\
\hline Delta $p$ (accoustic) & psia & $2.77 E-0 I$ & $0.00 \mathrm{E}+00$ & $2.40 \mathrm{E}-02$ & $1.00 \mathrm{E}-02$ & $1.00 \mathrm{~F}-02$ & $0.00 \mathrm{E}+00$ & $0.00 \mathrm{E}+\infty 0$ & $0.00 \mathrm{E}+\infty 0$ \\
\hline & & & & & & & & & \\
\hline Della Pult & psia & $1.16 E+00$ & $0.00 \mathrm{E}+00$ & $9.53 \mathrm{E}-01$ & $6.261 \% 01$ & $3.01 \mathrm{E}-01$ & $556 \mathrm{E}-02$ & $3.80 \mathrm{E}-0 \mathrm{I}$ & $7.00 \mathrm{E}-02$ \\
\hline Delta Puit- & psia & $-1.16 E+00$ & $0,00 \mathrm{~F}+00$ & $7.51 \mathrm{IE}-0 \mathrm{I}$ & $5.42 \mathrm{E}-0 \mathrm{I}$ & 2.17E-01 & $556 \mathrm{E}-02$ & $3.80 \mathrm{E}-01$ & $7.00 \mathrm{E}-02$ \\
\hline
\end{tabular}

Table 1: Vehicle loads at body station 413. 
maximum inward and outward pressure expected from the combination of aerodynamic pressure and three standard deviations of acoustic pressure, acting in either the positive or negative direction. A factor of safety of 1.4 was applied to the loads.

The ARMOR TPS design forms an aerodynamic shell that carries aerodynamic pressure on the TPS outer surface. The inside of the TPS panel is vented to local atmospheric pressure. In reality there may be variations between TPS internal pressure and local atmospheric pressure due to a pressure lag effect. However, data on this effect was not available, and the TPS internal pressure was assumed to equal local atmospheric pressure for preliminary sizing of TPS. This allows calculation of $\Delta \mathrm{P}_{\text {acrodynamic }}$ using the formula:

$$
\Delta P_{\text {uerodamamic }}=P_{\text {loxal-static }}-P_{\text {atmospheric }}
$$

where $P_{\text {local-static }}$ is the inward acting component of aerodynamic pressure and $P_{\text {atmospheric }}$ is the local atmospheric pressure at the current vehicle altitude. A positive values indicates inward acting pressure.

\section{Thermal-Mechanical Sizing}

Sizing of TPS outer sandwich panel layer and insulation layers required iteration between thermal analysis, structural static deflection analysis, and local honeycomb sandwich failure analysis. The process and criteria used is reported in Reference 5. The liftoff condition, highlighted in Table 1, dictated the structural design of the outer sandwich panel, and was dominated by acoustic pressure during liftoff. Saffil insulation sizing was driven by the reentry heating profile, and cryogenic foam insulation sizing was constrained by the ground hold heat flux into tank criterion.

After the sizing iterations were complete the following dimensions were obtained. The Saffil insulation thickness was 3.35 in. and the TEEK cryogenic foam insulation thickness was $0.75 \mathrm{in}$. The outer honeycomb sandwich panel was made of Inconel 617 with facesheet gage of 4 mils, and honeycomb specification (ribbon gage $x$ cell size) of 0.002 in. $x$ $3 / 16$ in. Honeycomb depth was determined to be 0.3 in. Reentry temperature histories for the finalized TPS dimensions are shown in Figure 9 at three locations inside the TPS / Tank system: the TPS surface, TPSS, and tank structure.
Reentry Tem peratures (STA 413 Windward Centerline)

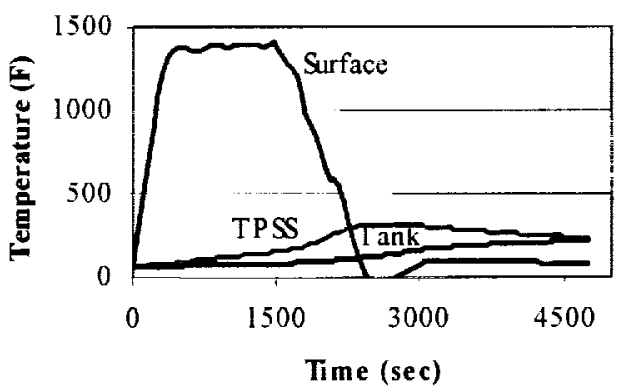

Figure 9: Reentry temperature histories.

\section{Accommodation of TPS and Tank Expansion}

During a flight cycle TPS and fuel tanks experience extremes in temperatures, from cryogenic temperatures to temperatures in excess of $1400^{\circ} \mathrm{F}$. In addition, fuel tank pressures range from $4.0 \mathrm{psi}$ to as much as 35.0 psi. The wide range of temperatures and pressures result in differences in expansion and contraction of the TPS and tank that must be accommodated to avoid damage to the TPS.

To determine the expansions expected in the system, a table of load cases (Table 2) was created recording the temperatures and pressures at various times during the vehicle flight cycle. For each load case the temperature of the tank and the titanium inner surface of the TPS and the tank pressure are listed. The displacements of the tank under a single TPS panel in the axial and hoop directions, the displacement of the inner TPS surface, and the difference between the tank and TPS displacements are also listed in Table 2.

The 15 load cases are grouped into three categories. The category labeled "Test Conditions" represents conditions expected during testing of the integrated test article, which combines the ARMOR TPS, TPSS, and a representative tank structure. The category labeled "Flight Conditions" represents conditions expected for the Wing/Cylindrical Body RLV during ascent and entry. Finally, the category labeled "On-orbit" represents possible bounds (A and B) of on-orbit temperature and tank pressures. 
Table 2: Calculation of Tank and TPS Expansions.

\begin{tabular}{|c|c|c|c|c|c|c|c|c|}
\hline $\begin{array}{l}\text { Load } \\
\text { Case }\end{array}$ & Description & $\mathrm{T}_{\mathrm{T} 1}\left(\mathrm{~F}^{\prime}\right)$ & $\mathrm{T}_{\text {TANK }}(\mathrm{F})$ & $\begin{array}{l}\text { Pressure } \\
\text { (psi) }\end{array}$ & $\begin{array}{l}\text { TPS Bolt } \\
\Delta[, 11 \text { (in) }\end{array}$ & $\begin{array}{l}\text { TPS Bolt } \\
\Delta \mathrm{L} 22 \text { (in) }\end{array}$ & $\begin{array}{c}\text { TPS Boltom } \\
\Delta L \text { (in) }\end{array}$ & $\Delta L l I-\Delta I$. (in) \\
\hline & Test Conditions: & & & & & & & \\
\hline 1 & Groundhold & 70 & 70 & 5 & 0.038 & 0.005 & 0.000 & 0.038 \\
\hline 2 & Groundhold & -140 & -423 & 5 & -0.034 & 0.019 & -0.033 & -0.002 \\
\hline 3 & Groundhold A & -140 & -423 & 14 & 0.001 & 0.035 & -0.033 & 0.033 \\
\hline 4 & Groundhold B & -140 & -423 & 35 & 0.081 & 0.072 & -0.033 & 0.114 \\
\hline \multirow[t]{2}{*}{5} & Worst Case Ileating & 250 & 250 & 5 & 0.086 & -0.004 & 0.029 & 0.057 \\
\hline & Flight Conditions & & & & & & & \\
\hline 6 & Aseent Max Fn $A$ & -100 & -423 & 14 & 0.001 & 0.035 & -0.027 & 0.027 \\
\hline 7 & Ascent Max Fn B & -100 & -423 & 35 & 0.081 & 0.072 & -0.027 & 0.108 \\
\hline 8 & Ascent Max T1-T2 A & -100 & -.423 & 14 & 0.001 & 0.035 & -0.027 & 0.027 \\
\hline 9 & Ascent Max T1-T2 B & -100 & -423 & 35 & 0.081 & 0.072 & -0.027 & 0.108 \\
\hline 10 & Entry Max Qdot $(t=453 \mathrm{~s})$ & 130 & 70 & 18.7 & 0.140 & 0.019 & 0.010 & 0.131 \\
\hline 11 & Entry $\mathrm{Max} \Delta \mathrm{P}(\mathrm{t}=1705 \mathrm{~s})$ & 210 & 86 & 18.7 & 0.143 & 0.018 & 0.023 & 0.121 \\
\hline 12 & Fntry Max $\Delta \mathrm{T}(\mathrm{t}=2355 \mathrm{~s})$ & 300 & 114 & 18.2 & 0.180 & 0.010 & 0.038 & 0.142 \\
\hline \multirow[t]{2}{*}{13} & Thermal Soak $(t=4355 \mathrm{~s})$ & 250 & 210 & + & 0.068 & .0 .003 & 0.029 & 0.039 \\
\hline & On orbit & & & & & & & \\
\hline $1+$ & $A$ & -250 & -250 & 18.7 & 0.037 & 0.039 & .0 .048 & 0.086 \\
\hline 15 & $B$ & 250 & 250 & 18.7 & 0.214 & 0.005 & 0.029 & 0.185 \\
\hline
\end{tabular}

Tank expansions were calculated assuming a 14 ply IM7/977-2 composite tank using $+/-65^{\circ}$ ply orientation. It was further assumed that the axial external blade stiffener height was 3 in. Tank expansion in the 1 and 2 direction (axial and hoop) are reported in the columns labeled "TPS Bolt $\Delta \mathrm{L} 11$ " and "TPS Bolt $\Delta \mathrm{L} 22$ ", which

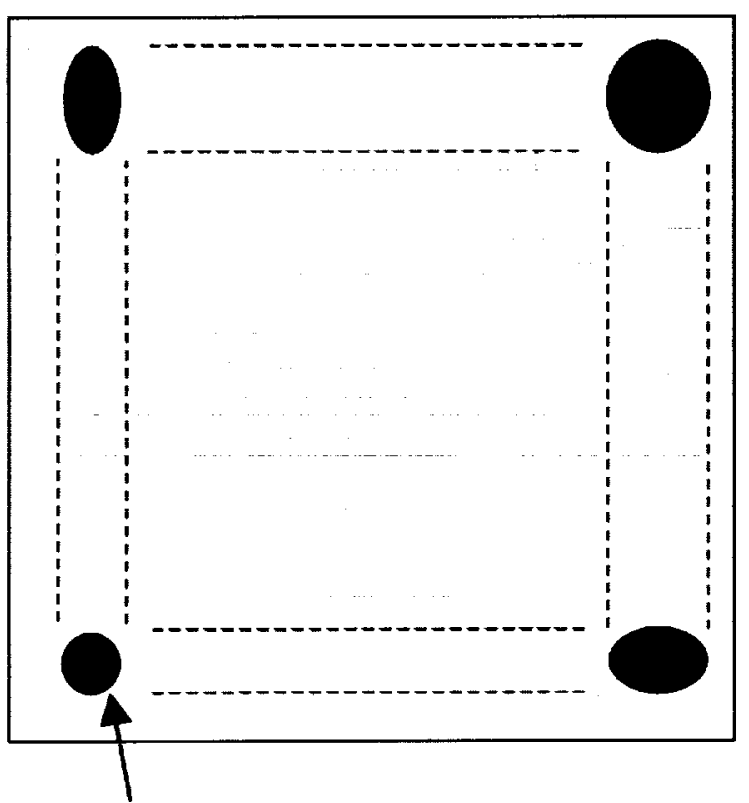

Fixed Point

Figure 10: Expansion slot pattern on bottom of TPS panel. represents the tank growth over an 18" span, the size of a single TPS panel. The term "TPS Bolt" signifies the TPS attachment bolts which mechanically attach the TPS at the four bottom comers to the external stiffeners.

The motion of the TPS bolts is directly coupled to the motion of the tank. The bolt at one corner of the

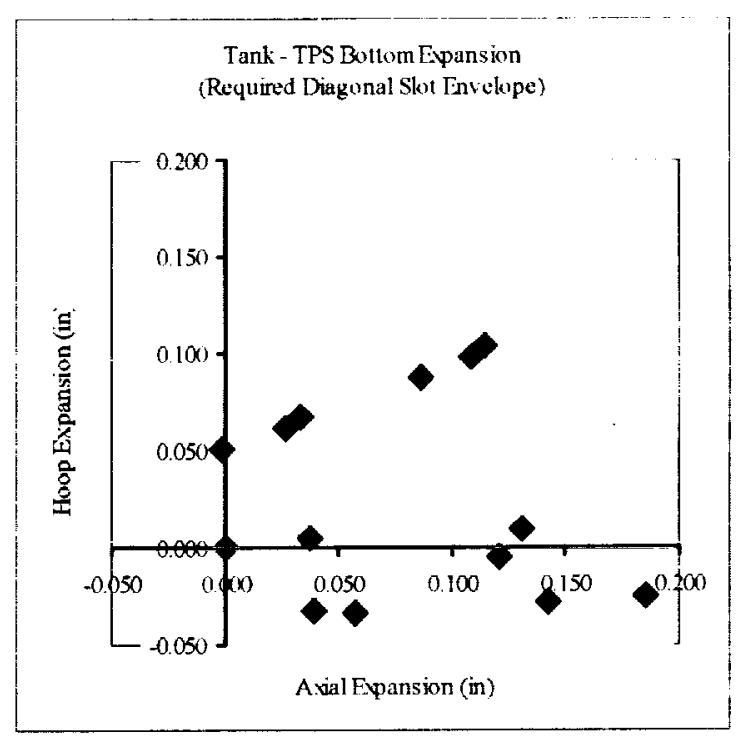

Figure 11: Plot of tank expansion relative to TPS expansion. 
TPS is fixed, as shown in Figure 10, but the bolts in the other comers are allowed to move due to expansion slots in the TPS bottom. The expansion slots are designed to constrain the translational and rotational degrees of freedom of the TPS panel while allowing free expansion relative to the tank. The required dimensions of the expansion slots were determined by plotting the quantities $\Delta \mathrm{L} 11-\Delta \mathrm{L}$ and $\Delta \mathrm{L} 22-\Delta \mathrm{L}$ as shown in Figure 11, where $\Delta \mathrm{L}$ is the expansion of the TPS bottom.

\section{Support Bracket Design}

As previously discussed, the comer support brackets are the most highly loaded and critical structural components of the ARMOR TPS panel. Each bracket has the conflicting requirements to: 1) provide an adequate structural connection between the outer honeycomb sandwich and the inner titanium frame, 2) limit the heat conduction between the hot outer surface and the cooler interior, and 3) accommodate the thermal expansion mismatch between the outer Inconel surface and the inner titanium frame. The design of a bracket was not straightforward. The basic design approach was to use a thin metal strip that could bend easily in one direction but not in other directions. The metal strips were located in the comers of the panel and arranged to be tangent to a circle about the center of the panel. In this way the outer honeycomb and the inner frame were free to expand thermally about the center of the panel with little resistance from the brackets connecting them. However, the brackets also had to resist compressive aerodynamic loading, so a stiffening bead was placed in the middle of the bracket, away from the ends, to prevent buckling. The ends of the bracket remained flexible enough to accommodate the thermal expansion mismatch. The bracket was made thin to reduce the amount of heat conducted from the outer surface to the interior and to keep the bending stiffness and stresses low.

Selecting the width, thickness and bead geometry for the brackets was not straightforward. A number of candidate geometries were chosen and analyzed with detailed finite element models to find one that was an acceptable compromise between the conflicting requirements.

The finite element analysis was completed using MSC/PATRAN and MSC/NASTRAN. Two critical load cases were analyzed for each bracket configuration: a hot load case and a cool load case. The hot case simulates a condition during reentry with the maximum surface temperature and negligible aerodynamic pressure. The peak temperature at the hot end of the bracket used for this analysis was $1533^{\circ} \mathrm{F}$. For the 18-in-square TPS panels, the thermal expansion mismatch between the outer surface at the maximum temperature and the inner titanium frame results in a displacement of 0.2 in. at the hot end of the bracket. For the cool load case the bracket must carry a compressive load resulting from a 2 psi pressure load on the outer surface.

One of the configurations analyzed was found to have acceptable stress levels with the least crosssectional area. The resulting dimensions of the bracket were 1 inch wide, 3 inches long, and 0.025 in. thick. The material selected for the bracket was Inconel 718 , because it has high yield stress and good creep resistance at elevated temperatures.

Results of the finite element analysis of the selected bracket geometry are shown in Figures 12 and 13 for the two load cases. Displacements and stress distributions are shown for both load cases.

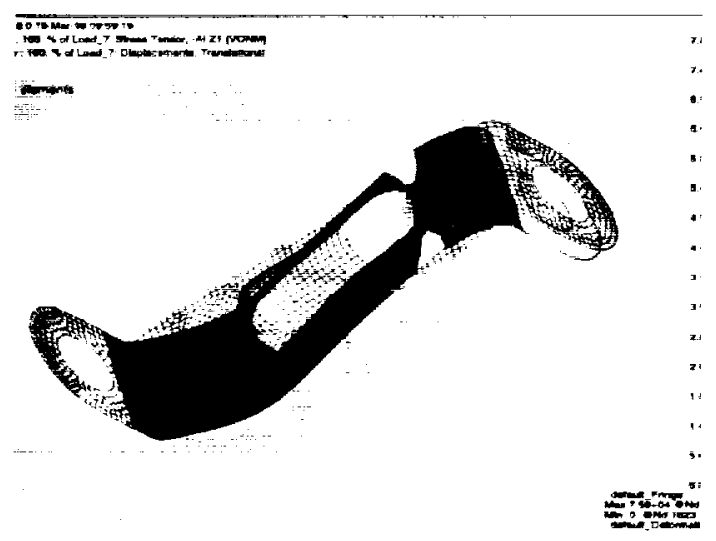

Figure 12: Stress distribution deformations for cool load case.

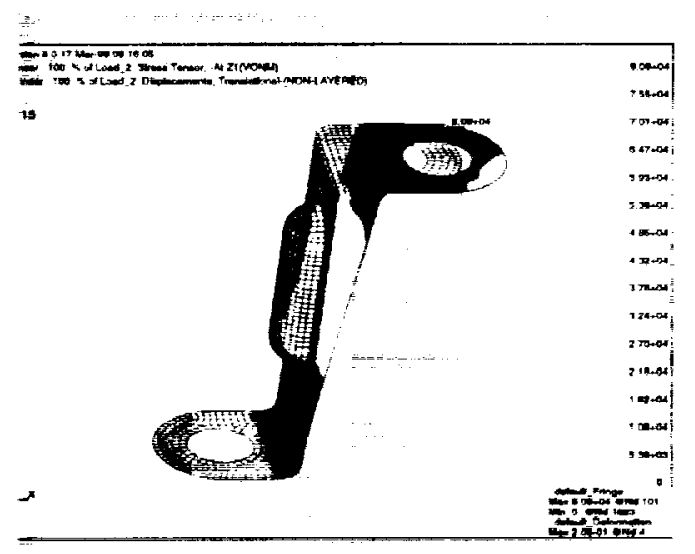

Figure 13: Hot case stress distribution.

Results for the cool load case are shown in Figure 12. The deformed shape indicates bracket bending 
under the applied compressive load. The maximum stress is $76 \mathrm{ksi}$, well below the $140 \mathrm{ksi}$ yield stress of Inconel 718 at room temperature. The critical buckling load was calculated to be 2.1 times the current load, so the bracket is safe from buckling under the 2 psi pressure loading.

Results for the hot load case are shown in Figure 13. The deformations show the transverse displacement at the hot end of the bracket that accommodates the expansion of the outer hot Inconel honeycomb sandwich. The maximum stress is $40 \mathrm{ksi}$, which is below the $50 \mathrm{ksi}$ yield stress for Inconel 718 at $1600^{\circ} \mathrm{F}$.

The bracket configuration was later modified to eliminate the bent ends. The straight ends are brazed into machined fittings, which eliminates some of the bending in the bracket and simplifies its shape. The modified support bracket shape was analyzed in subsequent creep analyses.

\section{Creep Analysis}

Creep deformation is a concern because the outer Inconel honeycomb sandwich and the four comer brackets react aerodynamic pressures while at elevated temperature. A NASTRAN finite element analysis was performed to investigate the occurrence of permanent deformations due to creep, creep rupture, and creep buckling.

The phenomenon of creep occurs when the strain in a material continues to increase under constant load There are generally three different stages of creep. Primary creep is transient creep during which the creep rate decreases over time. As the material deforms, the material strengthens via strain hardening, thus increasing the creep resistance and causing the decreasing creep rate observed. Primary creep gradually transitions into the second stage, referred to as steadystate creep in which the creep strain rate is a constant. The third stage is called tertiary creep and is characterized by an increasing creep rate.

The creep rate is dependent upon the stress, temperature, and time. The creep strength refers to the maximum employable stress level for the material at a prescribed temperature. This value of stress corresponds to a given level of creep (for example, 1 percent creep strain in 10,000 hours).

At the macroscopic level, the creep phenomenon is best observed in the uniaxial test under constant load and the relaxation test under constant strain at constant temperature. A specimen subjected to a constant uniaxial tension at an elevated temperature exhibits three distinct phases in a time frame: primary creep, secondary creep and the tertiary creep to rupture. If the specimen is unloaded after some creep deformation, the elastic strain is immediately recovered and a portion of the creep strain is gradually recovered. For metals, recoverable creep strain is generally negligible.

NASTRAN utilizes a creep analysis capability using a generalized viscoelastic model. The formulation is based on the step-by-step time integration of the Kelvin-Maxwell rheological model with non-constant parameters. If the plastic deformation is coupled with creep, the algorithm will seek a solution in two distinct steps. A number of empirical creep laws, recommended by the Oak Ridge National Laboratory (ORNL), are provided along with options for general tabular input of the rheological model parameters as functions of effective stress. When the creep characteristics are specified in terms of empirical creep laws, the program converts the empirical formula to the corresponding rheological model.

The NASTRAN creep analysis required either a creep law, such as an empirical exponential law, or tabular data and the calculated stresses. From the temperatures and the maximum stresses calculated in the finite element analysis, the rupture life can be estimated from creep properties for the materials used. If this rupture life is greater than the operation time (including a safety factor), the structure will be considered safe for creep. Alternatively, the time to reach $1 \%$ creep strain can be determined, to see if it is greater than the operation time. If so the structure will also be considered as safe for creep.

The components of the ARMOR TPS panel modeled for creep analysis consist of Inconel 617 honeycomb sandwich and Inconel 718 brackets. The 18-in-square honeycomb sandwich panel (with 0.004 in-thick facesheets and 0.3 in-thick core) is modeled as a 3-layer laminate. The bracket dimensions are 3 in. long by 1 in. wide by 0.02 in. thick with a bead. By taking advantage of two planes of symmetry in the ARMOR TPS panel only $1 / 4$ of the honeycomb panel and a single bracket is represented in the finite element model. The TPS panel is assumed to carry $0.52 \mathrm{psi}$ inward acting pressure load at $1750^{\circ} \mathrm{F}$ for 0.36 hour each mission. This loading is more severe than the station 413 loads of the current study, but was considered representative of loads for metallic TPS used nearer to its upper temperature limit.

Creep properties for Inconel 617 and 718 were obtained from Reference 13. For Inconel 718 creep properties were not available over the entire temperature range of interest. The following temperature effect correction equations ${ }^{14}$ were used to extrapolate the creep rates over the desired temperature range:

$$
\begin{aligned}
& \frac{\dot{\varepsilon}^{c}}{\dot{\varepsilon}_{o}^{c}}=X^{\left(\frac{T_{o}}{T}-1\right)} \\
& \text { where } X=e^{\left(\frac{-Q}{R T}\right)} \text { and }
\end{aligned}
$$


where $Q$ is energy of activation for creep. It can be determined graphically by plotting the natural logarithm of the minimum creep rate on the ordinate against the inverse of the absolute temperature on the abscissa. The slope of the isostress lines is equal to $-Q / R$, where $R$ is the universal gas constant.

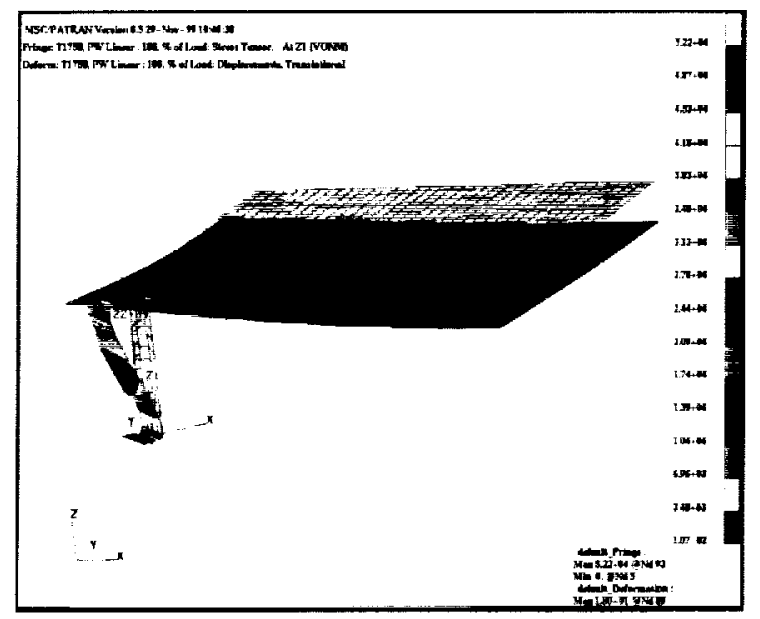

Figure 14: Stress distribution for static load and temperature.

Results of the NASTRAN creep analysis of the ARMOR TPS panel with Inconel 617 brackets are shown in Figures 14-17. Results are shown for static temperature and load, residual stresses and deformations after a single mission and stresses and deformations during and after 7 hours of loading at elevated temperature (approximately 20 missions). In all of the plots the deformations are greatly exaggerated for display.

Figure 14 shows the stress contours superimposed on the deformed shape resulting from the applied

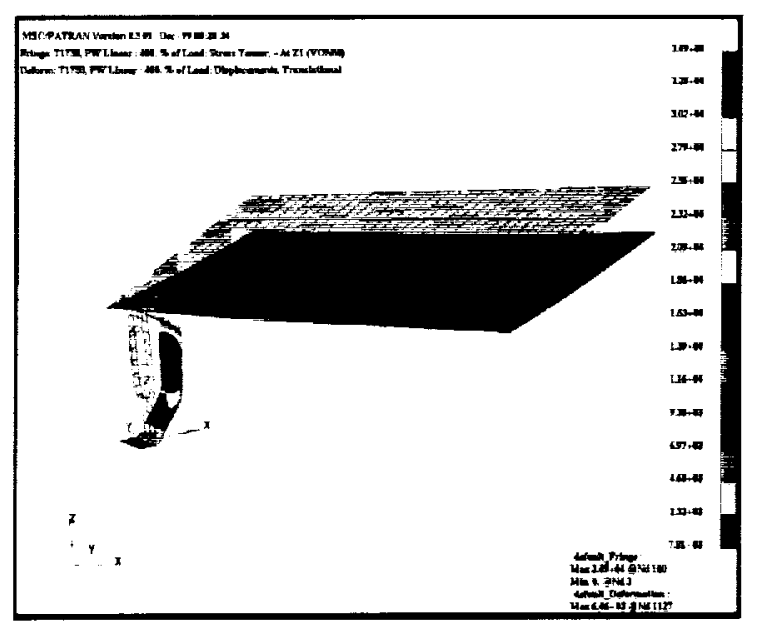

Figure 15: Stress after $1^{\text {st }}$ mission. temperature and pressure loading with no creep. As expected, the center of the panel (the comer opposite the bracket in this quarter symmetry model) deflects inward under the applied pressure loading. The hot end of the bracket is deflected radially outward from the panel center by the thermal expansion of the outer Inconel honeycomb sandwich. The peak stress of $\mathbf{5 2}$ ksi results from bending of the bracket near the hot end.

Figure 15 shows the residual stress distribution superimposed on the deformed shape of the panel after one mission. There is some inward residual deflection of the center of the panel. The bracket is bent at both ends so that it bows inward. The highest stresses (up to $35 \mathrm{ksi}$ ) are localized near the hot end of the bracket.

Figure 16 shows the stress distribution superimposed on the deformed shape of the panel after 7 hours of load at elevated temperature (approximately 20 missions). This stress distribution is shown while the panel is still at elevated temperature and under pressure loading. The deformation pattern and stress distributions are similar to those in Figure 14, however, the distribution in the bracket is different. The peak stress is reduced to $35 \mathrm{ksi}$ and is located near the cool end of the bracket. The peak stress near the hot end of the bracket is reduced to about $22 \mathrm{ksi}$.

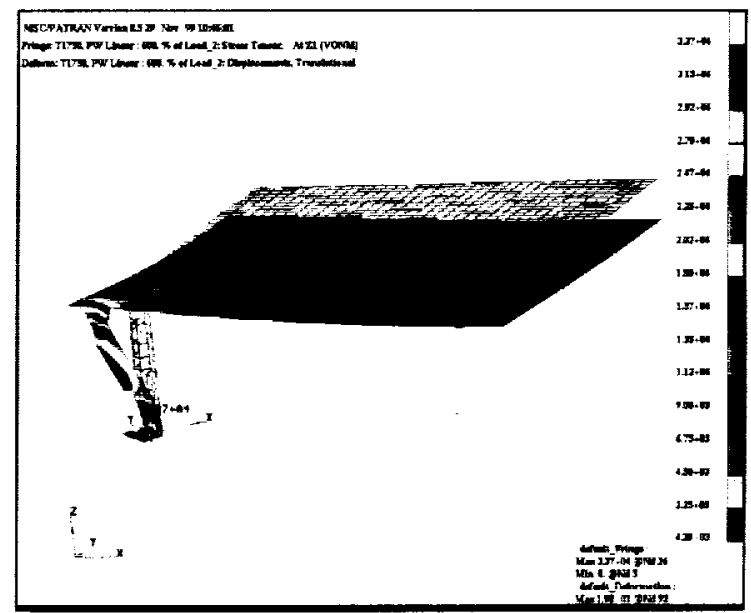

Figure 16: Stress distribution after 7 hours of loading.

Figure 17 shows the residual stresses superimposed on the deformed shape of the panel at room temperature under no load after 7 hours of exposure to elevated temperature loading. The center of the panel is displaced inward approximately 0.02 in. The flat portion of the hot bracket has developed a slight outward kink with a displacement of less than 0.03 in. The peak residual stress of $32 \mathrm{ksi}$ is located near the hot end of the bracket. 


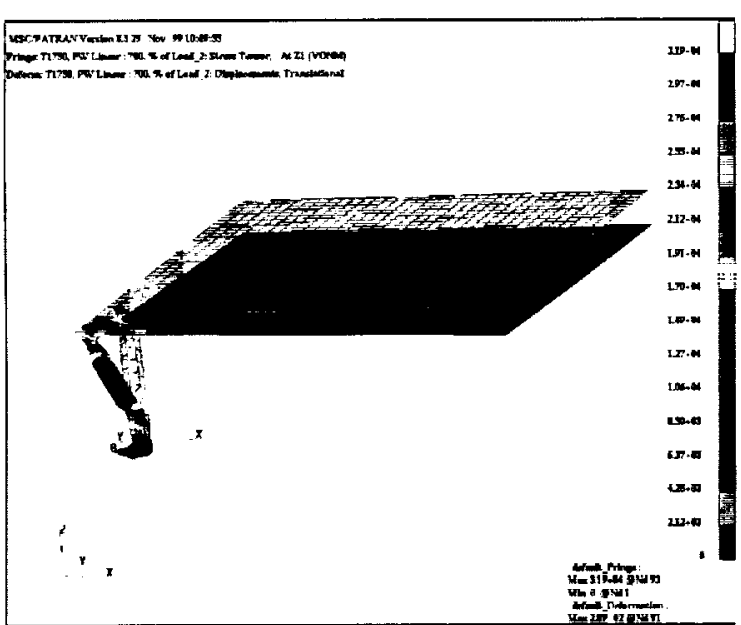

Figure 17: Residual stresses after 7 hours of loading.

The MARC program was also used to investigate the behavior of an ARMOR TPS panel with Inconel 718 brackets. MARC offered the capability of user written subroutines to readily incorporate the creep property extrapolations required for Inconel 718. This finite element model was used to define a temperature/pressure boundary, below which the current design has acceptable creep behavior. An example of one of the analyses used to develop the boundary is shown in Figure 18. The figure shows the deformation of the panel at the onset of creep buckling of the bracket after 17.6 hours (approximately 49 missions) at $1700^{\circ} \mathrm{F}$ and $0.65 \mathrm{psi}$. The location of the creep buckling is at the same location as the kink

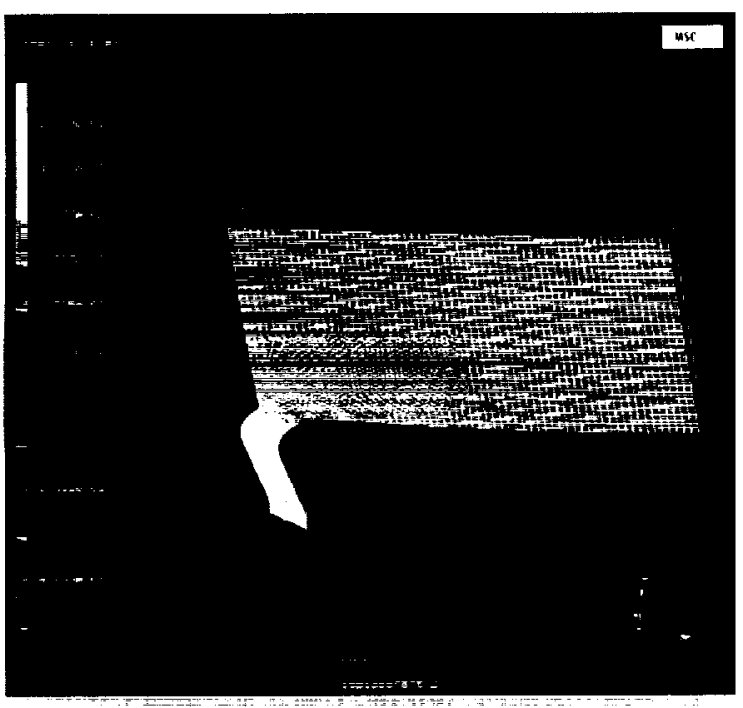

Figure 18: Deformation at the onset of creep buckling. observed in Figure 17

The predicted boundary of acceptable creep behavior for a current design of an ARMOR TPS panel with Inconel 718 brackets is shown in Figure 19. The area under the curve labeled "Acceptable" indicates that the panel was able to withstand the combination of temperature and pressure without violating any of the following conditions for the 100 mission life of the vehicle: 1) no creep buckling of the bracket, and 2) permanent deflections less than 1 percent of the diagonal span of the panel. The load conditions defined in Table 1 are well within the acceptable range. There is very little creep in the honeycomb sandwich and almost all the creep limitations are occurring in the bracket. Therefore, it may be possible to expand the temperature/pressure envelope by further refinement of the bracket design.

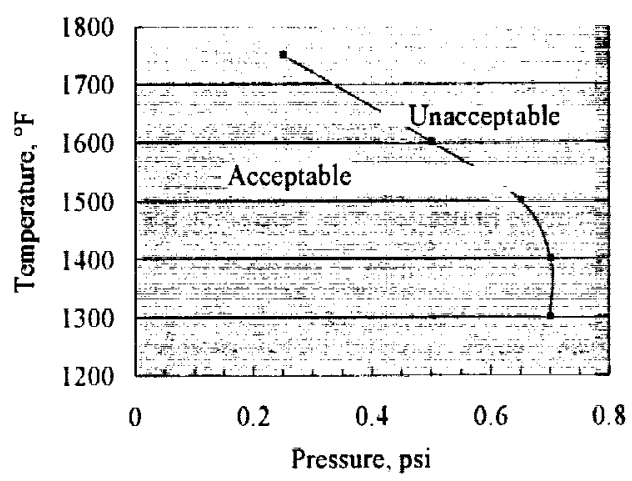

Figure 19: Creep boundary for current ARMOR TPS panel design.

\section{Fabrication and Testing}

\section{TPS Panels}

Four TPS panels with nominal dimensions of 18 inches by 18 inches by 3.5 inches were fabricated by BF Goodrich Aerospace, Aerostructures Group, using the previously discussed design. However, because of cost and scheduling constraints some material and foil gage substitutions were made. A picture of one of the TPS panels is shown in Figure 20. Each TPS panel consisted of an Inconel 617 honeycomb core sandwich panel on the top side (hot side), titanium alloy base (cool side), Inconel 625 standoffs and bolt access tubes, Saffil insulation, and a hybrid of Inconel 600 and commercially pure titanium (CP Ti) foil edge closeouts. Details of the brazing and superplastic forming 
processes used for panel fabrication are proprietary to BFG and are not reported in this paper.

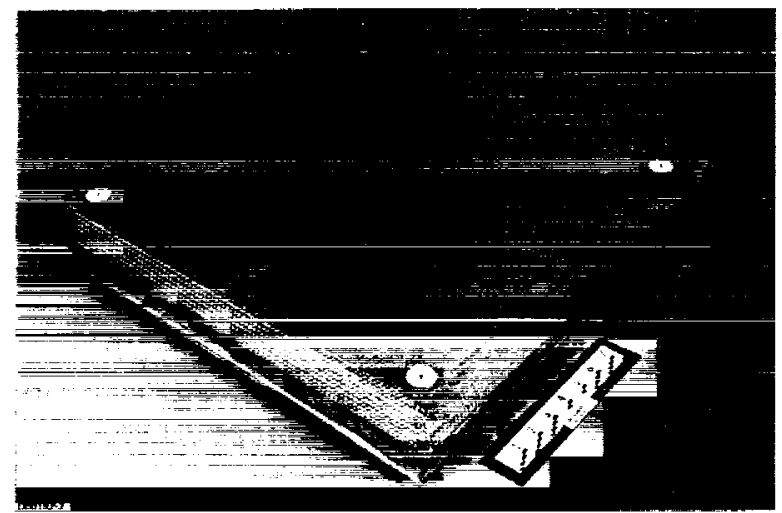

Figure 20: As fabricated ARMOR TPS panel.

Figures 21 and 22 show different views of the honeycomb core sandwich panel with corner inserts, standoff brackets, and bellows tubes installed. The honeycomb core sandwich panel for the hot surface was fabricated by brazing 0.006 -inch thick Inconel 617 foil face skins to an 18-inch by 18-inch Inconel 617 honeycomb core blanket. The honeycomb core blanket was 0.25 inch tall and had 3/16-inch corrugated square cells with 0.0015 -inch thick cell walls. The face skins on the extemal surface had a 1 -inch overhang along two edges of the honeycomb core to allow for overlapping seals with adjacent TPS panels when installed on the vehicle. Access holes were cut into the four corners of the sandwich panel and Inconel 625 inserts were installed into the holes. Three-inch long Inconel 625 standoff brackets and bellows tubes were brazed to the comer inserts in the honeycomb core sandwich panel. The standoff brackets set the internal dimension of the
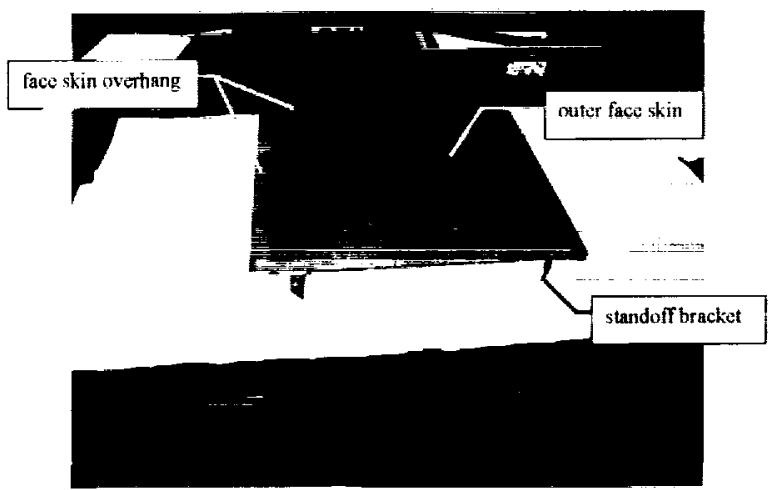

Figure 21: Inconel 617 honeycomb core sandwich panel with standoff brackets attached (top view). panel to allow 3 inches of insulation to be installed. The bellows tubes serve as seals for the bolt access holes through which the base of the panel will be bolted to the TPSS or vehicle structure

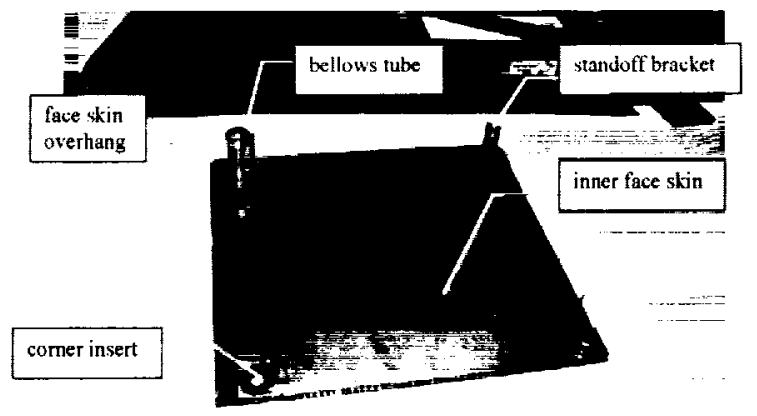

Figure 22: Inconel 617 honeycomb core sandwich panel with standoff brackets and one bellows tube attached (bottom view).

Figure 23 shows the base frame of the panel that was fabricated using superplastic forming of 0.010 -inch thick Ti-6Al-4V sheet to form a pan. The frame was cut out of the pan. Holes were cut into the four comers of the frame and Ti-6Al-4V inserts were installed (see Figure 24). These comer inserts in the base frame were brazed to the free ends of the bellows tubes and standoff brackets to form the skeleton of the TPS panel, as shown in Figure 25.

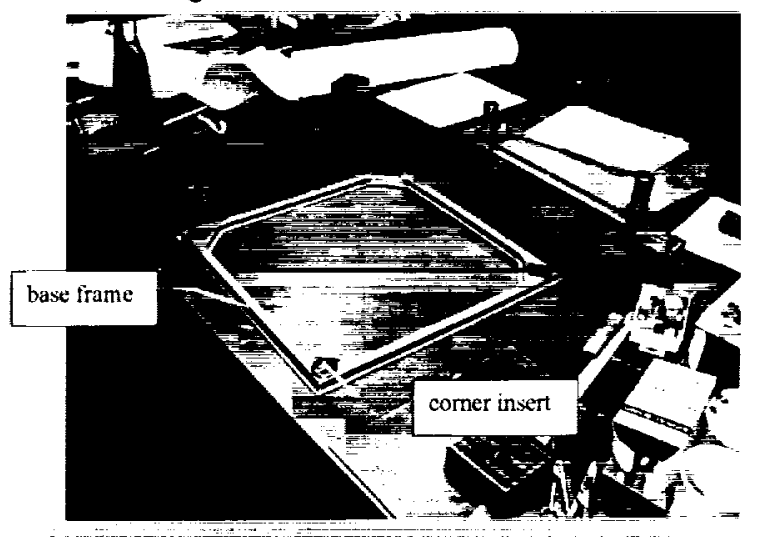

Figure 23: Ti-6Al-4V base frame cut from superplastically formed pan, with comer inserts installed (top view).

Once the TPS panel skeleton was assembled and brazed together, Saffil fibrous insulation with density of $3 \mathrm{lb} / \mathrm{ft}^{3}$ was installed into the panel's 3 -inch cavity. A 0.002 -inch thick sheet of $\mathrm{CP}$ Ti foil was brazed to the frame to close out the bottom of the base. A 1-inch diameter hole with fine-mesh screen was incorporated 


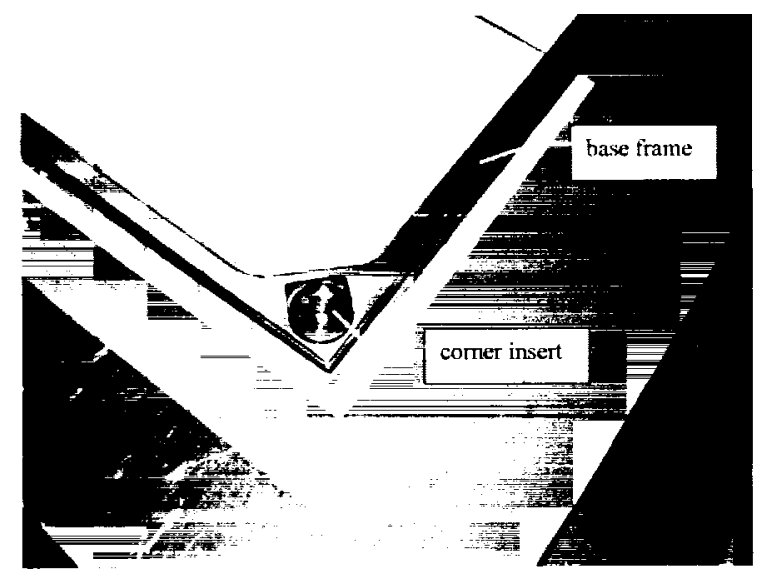

Figure 24: Enlarged view of corner insert installed in Ti-6 Al-4V base frame.

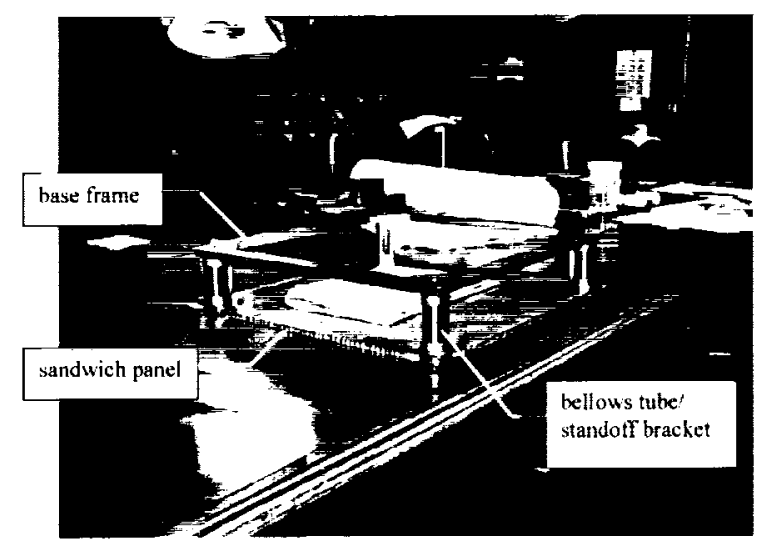

Figure 25: TPS panel assembly without insulation and edge and bottom closeouts (panel is oriented upside-down).

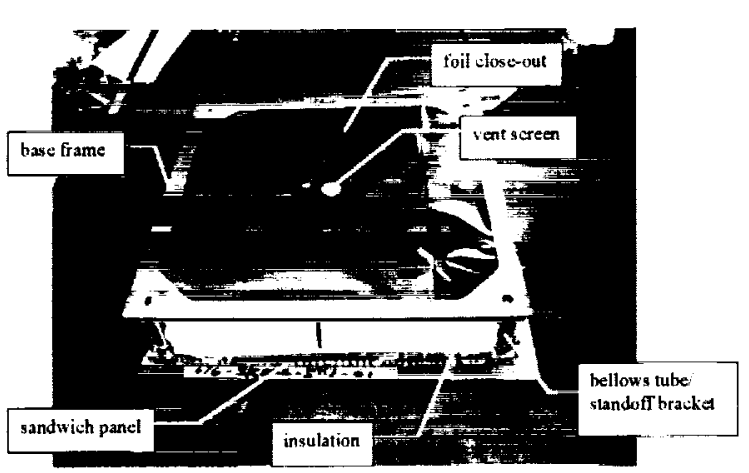

Figure 26: TPS panel assembly with insulation and bottom CP Ti foil closeout installed (bottom view).

into the center of the base closeout foil to allow venting of the TPS panel during service in reduced-pressure environments. Figure 26 shows the bottom view of the panel after the insulation was installed and the bottom was closed out. To complete the close-out of the top surface, removable Inconel 625 plugs and rings were machined and installed into the access holes in the honeycomb core sandwich panel.

The completed TPS panel is shown in figure 27. The panel edges were closed out with 0.002 -inch thick Inconel 600 foil and 0.002 -inch thick CP Ti foil. One end of the Inconel 600 foil was brazed to the underside of the outer face skin of the honeycomb core sandwich panel and one end of the $\mathrm{CP} \mathrm{Ti}$ foil was brazed to the base frame. The free ends of the Inconel 600 foil and the CP Ti foil were intercoiled together with braze foil along the midthickness and folded together at the comers of the TPS panel and brazed to form an airtight seam.

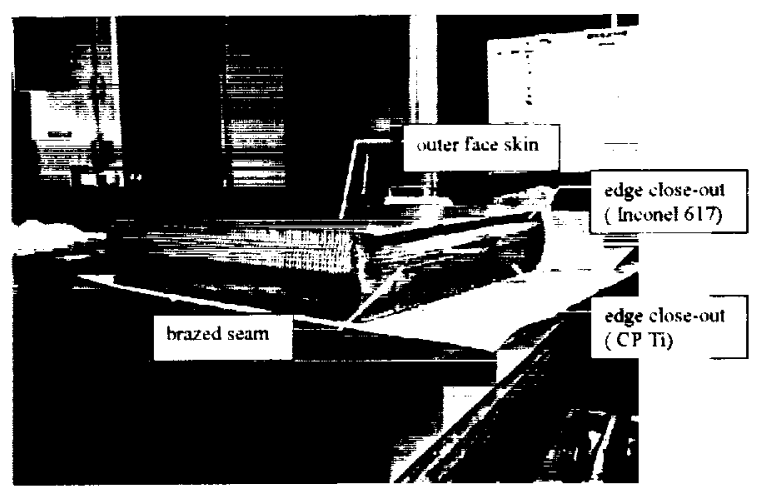

Figure 27: Completed TPS panel with edge closeouts (side view).

\section{Coatings}

An oxidation protection coating was applied to the external face skin of the TPS panels. The selected coating consisted of an alumina base layer and a twophase glass (TPG) outer layer with a total thickness of approximately $200 \mu \mathrm{in}$. The alumina layer prevents interaction between the Inconel 617 face skin and the silica-based TPG coating layer. The alumina and TPG precursors were produced using sol-gel techniques and sprayed onto the panel face skin. The coating layers were cured individually in air at approximately $1100^{\circ} \mathrm{F}$ for 5 minutes using a radiant heat lamp array. Details of the development and oxidation protection behavior of the coating system are discussed in References 15, 16 , and 17.

\section{TPS Support System}

A picture of the TPSS hardware assembly is shown in Figure 28. This hardware allows the attachment of a two-by-two array of flat TPS panels to a curved 


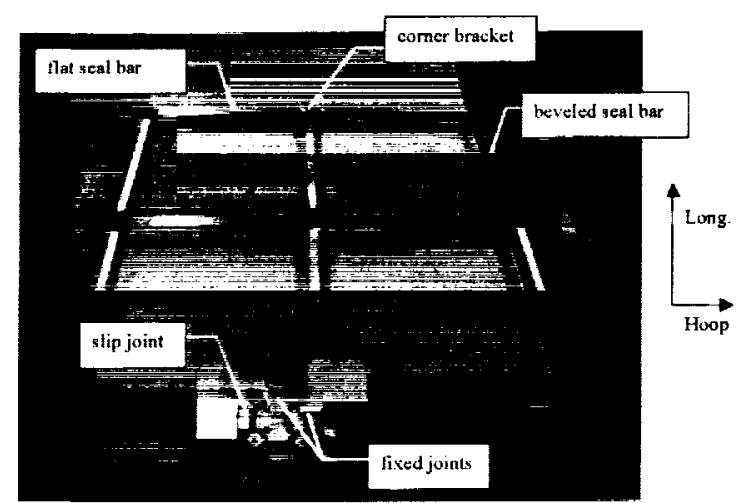

Figure 28: Ti-6Al-4V interface hardware.

externally-stiffened cryogenic tank panel. The bottom of the comer brackets are designed to be bolted to the caps of the tank panel T-stiffeners. The TPS panels rest on the seal bars and are bolted to the top of the corner brackets. Thin-gage (0.012-inch and 0.016-inch) Ti$6 \mathrm{Al}-4 \mathrm{~V}$ sheet was used to minimize the weight of the interface hardware components. The components were fabricated using conventional sheet metal forming and spot welding techniques. Each component of the interface hardware consisted of multiple subelements that were cut to size, formed to the appropriate configurations, and spot welded together in order to provide the various flanges, slip joints, attachment points, and sealing surfaces.

Figure 29 shows some of the tooling, sheet metal subelements, and formed channels used to fabricate the seal bars and corner brackets. One completed comer bracket/seal bar assembly is also shown in the figure.

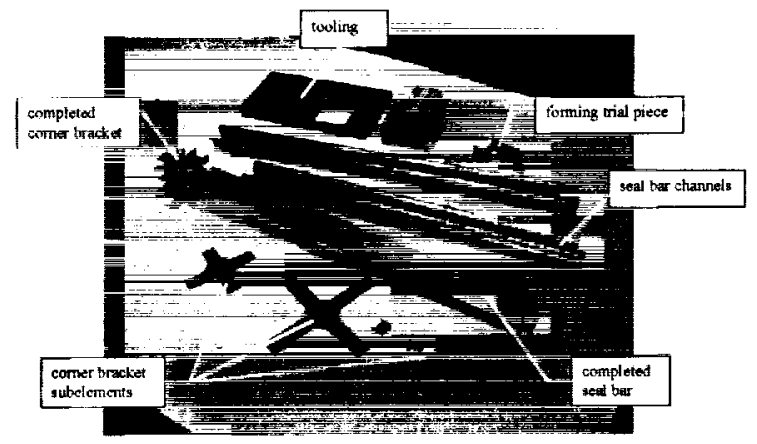

Figure 29: Tooling, subelements, and channels used to fabricate Ti-6Al-4V comer brackets and seal bars for interface hardware.

\section{Planned tests}

The metallic TPS system will be subjected to two different series of tests to evaluate the insulating capabilities of this TPS design as well as thermal expansion behavior relative to the various substrate panels and interface hardware. In one test series, a two-by-two array of TPS panels will be attached to a full-scale (76-in by 65 -in) externally-stiffened curved graphite-epoxy composite cryogenic propellant tank panel using the comer bracket and seal bar interface hardware. This TPS panel array will cover approximately $25 \%$ of the cryogenic tank panel surface. The remainder of the surface will be covered with thermal insulation blankets. This integrated panel will be tested in the Cryogenic Pressure Box Facility at LaRC to simulate launch vehicle ground hold and ascent conditions. The tank panel will be pressurized to representative tank pressures at cryogenic temperatures. Hoop and longitudinal mechanical loads will be applied to the tank panel and external thermal loads will be applied to the TPS using a radiant heat lamp array. The maximum temperature attainable in this test system is $1000^{\circ} \mathrm{F}$, so reentry conditions cannot be simulated in the series of tests.

The second test series will involve evaluating two TPS panels attached side-by-side to 36 -in by 18 -in flat substrate panels constructed from various candidate cryogenic tank materials. These substrate panel materials include aluminum-beryllium alloys and polymer composites, as well as an aluminum alloy to serve as a baseline. These test articles will be configured with the TPS panels bolted directly to the substrate panel skin and with the TPS panels attached to the substrate panel stiffeners using the interface hardware to evaluate differences in these two attachment schemes. These tests will be conducted in the Thermal Vacuum Test Facility at LaRC that consists of a 5-foot diameter vacuum chamber enclosing a radiant heat lamp array with temperature capability of $1800^{\circ} \mathrm{F}$. This test facility will be used to simulate reentry conditions by using reduced ambient pressure and applying a simulated entry high temperature thermal profile to the external skin of the TPS panels. Neither mechanical loads nor cryogenic temperatures will be applied to the test articles during this series of tests.

\section{$\underline{\text { Summary }}$}

A new Adaptable, Robust, Metallic, Operable, Reusable (ARMOR) thermal protection system (TPS) concept has been designed, analyzed and fabricated. In addition to the inherent, tailorable robustness of metallic TPS, the ARMOR TPS offers improved features based on lessons learned from previous metallic TPS development efforts. ARMOR TPS panels may be attached directly to a smooth substructure or supported on TPS support structure 
above an externally stiffened or uneven substructure. Bulged, compliant sides minimize or eliminate radiation heat shorts in the panel-to-panel gaps. Innovative, internal support brackets provide a structural load path between the hot outer surface and cooler interior without causing unacceptable heat shorts yet allow free thermal expansion of the outer surface. Cool, subsurface mechanical fasteners provide reliable, reusable attachments. The outer Inconel honeycomb sandwich facesheets can be readily thickened to achieve required levels of robustness.

A specific location on a single-stage-to-orbit reusable launch vehicle was selected to develop loads and requirements needed to design prototype ARMOR TPS panels. The design loads include ascent and entry heating rate histories, pressures, acoustic loads, and accelerations. Critical thermal/structural design loads were identified at 8 points during the ascent and entry. Additional TPS design issues were identified and discussed.

An iterative sizing procedure was used to size the ARMOR TPS panels for thermal and structural loads as part of an integrated TPS/cryogenic tank structural wall. The TPS panels were sized to maintain acceptable temperatures on the underlying structure and to withstand the design structural loading. Detailed creep analyses were also performed on critical components of the ARMOR TPS panels. A TPS support system for connecting the ARMOR TPS panels to the externally stiffened cryogenic tank structure was also designed.

Four 18-inch-square ARMOR TPS panels and associated TPS support system hardware were fabricated. Materials, dimensions and fabrication processes are described. Test plans for the fabricated hardware are presented.

ARMOR TPS provides an attractive solution for the next generation of reusable launch vehicles that are striving for economic viability. The robust ARMOR TPS panels offer the potential to greatly reduce maintenance costs and increase the range of weather conditions acceptable for flight compared to competing TPS alternatives.

\section{References}

1 Cook, S. A.: The X-33 Advanced Technology Demonstrator, AIAA-96-1195, April 1996.

${ }^{2}$ Blosser, M. L., "Advanced Metallic Thermal Protection Systems for Reusable Launch Vehicles", Ph. D Dissertation, UVA, May 2000

${ }^{3}$ Dorsey, John T.; Chen, Roger; and Poteet, Carl: "Metallic Thermal Protection System Technology Development Concepts, Requirements and Assessment Overview," $40^{\text {th }}$ AIAA Aerospace Sciences Meeting and Exhibit, Reno, NV, January 14-17, 2002.

${ }^{4}$ Dorsey, John T.; Myers, David E.; and Martin, Carl J Reusable Launch Vehicle Tank/Intertank Sizing Trade Study. Presented at the $38^{\text {th }}$ Aerospace Sciences Meeting and Exhibit, January $10-13,2000 /$ Reno, Nevada. Available as AIAA 2000-1043

5 Poteet, C. C.; Abu-Khajeel, H; and Hsu, S-Y: Preliminary Thermal-Mechanical Sizing of Metallic TPS: Process Development and Sensitivity Studies. $40^{\text {th }}$ Aerospace Sciences Meeting and Exhibit, January 14-17, 2002/ Reno NV.

${ }^{6}$ Hender, D.R.: "A Minature Version of the JA-70 Aerodynamic Heating Computer Program, H800 (MINIVER)," McDonnell Douglas Astronautics Co., Huntington Beach, CA, MDC Report G0462, June 1970 (revised Jan. 1972).

${ }^{7}$ Blosser, M.L.: Investigation of Fundamental Modelling and Thermal Performance Issues for a Metallic Thermal Protection System. $40^{\text {th }}$ Aerospace Sciences Meeting and Exhibit, January $14-17,2002 /$ Reno NV, AIAA 2002-0503.

${ }^{\mathbf{g}}$ Weiser, Erik S ; et al: "Polyimide foams for aerospace vehicles," High Perform. Polym., 2000.

'Chen, R.R.; and Blosser, M.L.: "Metallic Thermal Protection System Panel Flutter Study," $40^{\text {th }}$ Aerospace Sciences Meeting and Exhibit, January $14-17,2002 /$ Reno NV, AIAA 2002-0501

${ }^{10}$ Kennard, E. H.: Kinetic Theory of Gases, McGraw - Hill, New York, 1938

${ }^{11}$ Swann, R. T., and Pittman, C. M., "Analysis of Effective Thermal Conductivites of Honeycomb-Core and Corrugated-Core Sandwich Panels," NASA TN D-714, April, 1961

${ }^{12}$ Poteet, C. C., "Groundhold and Reentry Purge Parameter Trade Study," Lockheed Martin, Langley Program Office, Hampton, VA, LMES SDSR 99-01, 1999.

${ }^{12}$ Brown, Jr, W.; Mindlin, H.; and Ho, C., editors: Aerospace Structural Metals Handhook, CINDAS/USAF CRDA Handbook Operation, Purdue University, West Lafayette, IN, 1994.

${ }^{14}$ Taminger, Karen M. B.: "Analysis of Creep Behavior and Parametric Models for $2124 \mathrm{Al}$ and $2124 \mathrm{Al}+\mathrm{SiCw}$ Composite," M Sc. Thesis, VPI\&SU, February 1999.

${ }^{15}$ Bird, R.K.; Wallace, T.A.; and Sankaran, S.N.: Effect of Oxidation on Properties and Microstructure of Candidate Alloys for Reusable Launch Vehicle Thermal Protection Systems. Paper B08, Proceedings of the $25^{\text {th }}$ Annual Conference on Composites, Materials, and Structures, January 22-26, 2001, Cape Canaveral, Florida.

${ }^{16}$ Sankaran, S.N.; Wiedemann, K.E.; Bird, R.K.; and Wallace, T.A.: Development of Protective Coatings for 
Thermal Protection Systems for Reusable Launch Vehicle Applications. Paper B09, Proceedings of the $25^{\text {th }}$ Annual Conference on Composites, Materials, and Structures, January 22-26, 2001, Cape Canaveral, Florida.

${ }^{17}$ Bird, R.K; Wallace, T.A; and Sankaran, S.N.: Development of Protective Coatings for HighTemperature Metallic Materials. Elevated Temperature Coatings: Science and Technology IV, N.B. Dahotre J.M. Hampikian, and J.E. Morral, eds. The Minerals, Metals, and Materials Society, pp.181-196, $200 \mathrm{I}$. 